\title{
Les réactions du Midi : conflits, continuités et violences
}

\section{Stephen Clay}

\section{(2) OpenEdition \\ 1 Journals}

Édition électronique

URL : https://journals.openedition.org/ahrf/6923

DOI : $10.4000 /$ ahrf.6923

ISSN : 1952-403X

\section{Éditeur :}

Armand Colin, Société des études robespierristes

\section{Édition imprimée}

Date de publication : 1 septembre 2006

Pagination : 55-91

ISSN : 0003-4436

\section{Référence électronique}

Stephen Clay, "Les réactions du Midi : conflits, continuités et violences », Annales historiques de la Révolution française [En ligne], 345 | juillet-septembre 2006, mis en ligne le 01 septembre 2009, consulté le 01 juillet 2021. URL : http://journals.openedition.org/ahrf/6923 ; DOI : https://doi.org/ 10.4000/ahrf.6923

Ce document a été généré automatiquement le 1 juillet 2021.

Tous droits réservés 


\title{
Les réactions du Midi : conflits, continuités et violences
}

\author{
Stephen Clay
}

Dans le Midi provençal, les troubles révolutionnaires furent précoces, multiples et durables ${ }^{1}$. Depuis le printemps 1789 jusqu'à la fin de la décennie révolutionnaire, et même au-delà, les départements des Bouches-du-Rhône, du Vaucluse et du Var en particulier, furent le théâtre d'une violence individuelle et collective d'origine essentiellement politique, d'une ampleur telle qu'elle choqua aussi bien les contemporains que les historiens par la suite. La série quasi ininterrompue de meurtres, massacres, émeutes et insurrections - sans parler des épisodes sanglants de la Terreur - conféra à cette région l'étiquette bien méritée d'extrémisme politique. « Du sang, toujours du sang, voilà malheureusement toujours le mot qui se présente sous la plume de celui qui a à rendre compte de ce qui se passe dans le Midi ", écrivait le journal parisien, la Gazette française, dans la même veine que beaucoup de commentaires de l'époque ${ }^{2}$. Cette violence fut principalement l'expression et la conséquence de la lutte incessante des factions ou partis ${ }^{3}$. Dès le début de la Révolution, deux groupes rivaux, parfois plus - ce que les contemporains eux-mêmes appelaient la «lutte des deux partis » ou des factions - que séparaient habituellement les positions idéologiques, les codes vestimentaires, les signes de ralliement et chansons, et même leurs propres cafés, s'engagèrent dans une lutte de pouvoir largement socioéconomique où les alliances de quartier et de voisinage constituaient une donnée essentielle. Pendant chaque phase de la Révolution - la Révolution en Provence aussi bien qu'ailleurs étant caractérisée par des phases - chaque parti se voyait tour à tour oppresseur et opprimé. Les actions et réactions de ces factions entraînèrent chaque étape de la Révolution dans une lutte de pouvoir apparemment interminable, qui engendra un lourd héritage de haine et une tradition de violence. Dans les affaires politiques de la région, les différentes phases de la Révolution furent en grande partie le produit de conflits préexistants, qui impliquaient bien souvent les mêmes hommes, leurs familles et amis, ainsi que leurs alliés, dans un combat politique intense aussi polarisé que personnalisé. 
2 La période communément appelée la « réaction » figure parmi celles qui sont le plus souvent associées avec le Midi provençal, tant par les contemporains que par des commentateurs postérieurs ${ }^{4}$. C'est en effet dans cette région que la réaction, du point de vue de ses manifestations politiques, fut la plus marquée. Le terme de réaction, au sens politique et au niveau local aussi bien que national, commença à être employé fréquemment juste après la chute de Robespierre ; jusqu'alors dans les dictionnaires du $\mathrm{XVIII}$ e siècle et dans le langage courant, le mot "réaction " était presque toujours utilisé dans un sens physique et non politique comme une réponse à une action. Sous Thermidor et le Directoire, le terme prit une connotation politique dans la correspondance, les discours, les pamphlets et les mémoires de l'époque. Ce seront les Mémoires de Fréron sur la réaction royale et les Réactions politiques de Benjamin Constant qui en généraliseront l'usage comme concept politique. Le mot fut rapidement adopté dans l'historiographie officielle nationale et locale de la Révolution tout au long des XIX et $\mathrm{XX}^{\mathrm{e}}$ siècles ${ }^{5}$. Souvent employé comme synonyme de Terreur blanche - cette période spécifique largement limitée à l'an III et caractérisée par de violentes attaques contre les hommes et les institutions de l'an II - le terme de réaction était invariablement lié au Midi, et surtout aux départements des Bouches-du-Rhône et du Vaucluse. En outre, dans la majorité des écrits sur la région, qu'ils soient l'œuvre d'observateurs contemporains ou d'historiens postérieurs, le phénomène de « réaction » était décrit comme fondamentalement royaliste, hostile à la République et aux républicains. Cette interprétation de la réaction comme essentiellement royaliste, une Terreur blanche par opposition à une Terreur rouge, a longtemps perduré dans l'historiographie du XX' siècle.

3 Pourtant, tant d'un point de vue politique que chronologique, la réaction s'avère un phénomène plus complexe. L'interprétation faisant de la réaction du Midi un mouvement principalement royaliste, circonscrit à l'an III, occulte autant la complexité du concept que sa réalité. En effet, décrire la réaction comme exclusivement ou même fondamentalement royaliste revient à souscrire à une lecture tendancieuse des événements qui mélange discours et réalité, autrement dit à accepter que le langage de la vie politique contemporaine définisse la représentation historique des événements.

4 Ainsi, au printemps et à l'été 1795 , la persécution des anciens terroristes et de leurs sympathisants fut de plus en plus dénoncée comme une violence royaliste au même titre que le retour des émigrés et des prêtres réfractaires. À la fin de l'an IV, l'adjectif «royaliste » était devenu indissociable de ce qu'on pourrait appeler le discours néojacobin, dans lequel il servait à désigner les violences antijacobines pendant tout le Directoire $^{6}$. Les termes "royaliste" et "royalisme", en effet, faisaient partie intégrante du répertoire d'appellations utilisé par les Jacobins pour stigmatiser leurs adversaires, et entraient dans une stratégie linguistique ayant pour objet la légitimation, la solidarité de groupe et la politique d'exclusion. Cette pratique n'était pas nouvelle: depuis les premières années de la Révolution, en effet, les termes fortement connotés d' " aristocrate », " contre-révolutionnaire » ou "modéré », entre autres, étaient utilisés par les Jacobins, alors que leurs adversaires traitaient fréquemment ceux-ci d'" anarchistes » ou de " buveurs de sang ».

5 Cela ne veut pas dire qu'il n'existait pas de sentiments royalistes, à divers degrés et sous différentes formes, chez les hommes et les femmes du Sud-Est avant et après Thermidor. Des preuves, en effet, démontrent l'existence de mouvements contrerévolutionnaires - jamais complètement unis - dans le Haut-Comtat, ou chez certains 
individus comme Pascalis, d'Aix, ou Saint-Christol, du Vaucluse. Le gouvernement britannique avait lui aussi ses agents parmi les habitants du Sud-Est, bien que leur activité ait été bien plus limitée qu'ailleurs ${ }^{7}$. D'autres aussi ont pu aspirer à renverser les régimes révolutionnaires ou à espérer le retour des temps anciens. Mais, comme bien souvent, ces convictions, pour des raisons évidentes, n'étaient pas professées ouvertement. D'où la difficulté à déterminer la véritable nature de toute action identifiée comme contre-révolutionnaire. Certes, de nombreux habitants de la région manifestèrent leur lassitude face à la durée, aux troubles et aux traumatismes engendrés par la Révolution. Le journaliste marseillais Ferréol Beaugeard, entre autres, écrivant après plusieurs années de Révolution pendant lesquelles il avait lui aussi joué un rôle actif de journaliste et d'acteur politique, l'exprimait ainsi : «Espérons que nous allons sortir de cet état de lutte pénible et continuelle dans lequel nous nous traînons depuis sept ans. S'il faut toujours voir une vengeance succéder à une vengeance, et une réaction amener une réaction, il vaut mieux vivre dans les bois $»^{8}$. Beaucoup manifestèrent une irritation croissante face aux excès qu'ils associaient à la politique jacobine. Et il est vrai que pendant toute la période révolutionnaire, en particulier après Thermidor, les attaques exercées contre les membres des sociétés populaires et ceux identifiés comme "patriotes" et «républicains", constituèrent une caractéristique commune de la violence politique de la région, et de la France entière, notamment dans les régions de Lyon et de la vallée du Rhône profondément touchées par l'expérience de la Terreur'. Mais l'accusation souvent avancée par les Jacobins locaux selon laquelle les auteurs de ces actes de violence étaient des royalistes et des contre-révolutionnaires, et que des hommes parfois même au sein des tribunaux et des administrations des Bouches-du-Rhône fomentaient une contre-révolution, reste plus l'expression du langage et de la perception de la politique des factions qu'une réalité historique. Le sentiment prédominant de l'an III et des années qui suivirent, dans ce département des Bouches-du-Rhône, n'était pas royaliste mais antiterroriste ou anticlubiste ; il avait comme source le ressentiment et comme motif la vengeance.

Certains anciens Jacobins et leurs partisans dans le Midi parlaient de "la réaction" pour caractériser la persécution, singulière et sanglante, qu'ils avaient continuellement subie depuis le 9 Thermidor jusqu'à la fin du Directoire ; d'autres membres de ce parti, surtout dans les Bouches-du-Rhône, distinguaient deux réactions: deux vagues de violence intense, deux réactions royales - celle de l'an III et celle de l'an $\mathrm{V}^{10}$. Ces réactions avaient des caractéristiques communes : en partie initiées et tolérées par des personnalités envoyées officiellement de Paris dans la région - au premier rang desquelles le représentant Paul Cadroy et le général de la 8e division militaire Amédée Willot -, et bénéficiant de la complicité de nombreux fonctionnaires publics locaux et du personnel judiciaire (principalement les juges de paix et les directeurs du jury), ainsi que des commandants militaires, ces réactions se caractérisaient par un féroce antiterrorisme, voire un anti-jacobinisme virulent, souvent amalgamés, impliquant la plupart du temps les mêmes bourreaux et les mêmes victimes. Pour les Jacobins menacés, ces réactions incarnaient la persécution des républicains par les royalistes.

7 Les adversaires des Jacobins, en revanche, qu'ils aient été modérés, fédéralistes, victimes de la Terreur, émigrés, membres de l'élite de l'Ancien Régime ou authentiques royalistes, avaient un tout autre point de vue sur les réactions. Il était possible, selon eux, d'identifier deux autres réactions touchant la région pendant ces années, réactions que les Jacobins et les anciens terroristes eux-mêmes avaient perpétrées contre leurs opposants politiques en l'an IV et en l'an VI. Durant ces réactions « jacobines », les rôles 
furent inversés: les anciens Jacobins, les terroristes et leurs sympathisants, des personnages comme Stanislas Fréron envoyés dans la région en l'an IV, ainsi que des Jacobins locaux rétablis dans leurs fonctions administratives, judiciaires ou militaires en l'an VI et VII, persécutèrent ceux qui, à maintes reprises, les avaient persécutés auparavant. En bref, les réactions de Thermidor et du Directoire constituaient des luttes de factions qui n'en portaient pas le nom.

8 Le terme "réaction» ou, au pluriel, "réactions», en vint donc à désigner les changements de pouvoir et de personnes, brutaux, idéologiques, voire violents, par lesquels une faction remplaçait l'autre. Chaque camp minimisa systématiquement ou nia tout bonnement, la sévérité de la réaction affectant la faction opposée. Et tous les partis reconnaissaient que les réactions n'étaient pas le simple produit de facteurs et d'individus locaux, mais qu'elles avaient été provoquées, du moins tolérées, par des personnalités envoyées de Paris dans la région sous la Convention thermidorienne et le Directoire, qu'il s'agisse de représentants en mission ou de généraux de la 8e division militaire. Quels que soient la réaction et le parti dominant, les membres des factions en guerre reconnaissaient que la lutte des deux partis et le désir de vengeance entretenaient le conflit.

9 Ces réactions définirent la politique locale sous la Convention thermidorienne et le Directoire, en particulier dans le département des Bouches-du-Rhône. S'inscrivant dans la continuité de conflits préexistants entre des factions rivales dont la haine mutuelle était intensifiée par la révolte fédéraliste et la Terreur - événements qui marquèrent profondément l'histoire de la région comme le reste de la France - les réactions doivent donc être analysées, ainsi que le firent les contemporains, comme un produit de facteurs nationaux et locaux. Ces facteurs incluaient aussi bien des institutions que des personnalités, le plus souvent des figures locales utilisant des institutions nationales comme un instrument dans la politique de la lutte des factions.

10 Le "jeu de la politique locale» se déroulait avec l'aide des autorités militaires, administratives et judiciaires ${ }^{11}$. C'est précisément par l'interaction de ces pouvoirs électifs ou nominatifs - que l'on peut pleinement appréhender la dynamique de la vie politique locale à cette période. Il faut néanmoins ajouter que l'utilisation - parfois abusive - de ces institutions par les factions constituait déjà une caractéristique des premières années de la Révolution. En effet, dans le département des Bouches-duRhône en particulier, c'est la continuité du conflit qui constitue la principale clé de compréhension de la période. Cet article montrera comment le système de réactions façonna l'histoire politique d'une partie du Midi provençal pendant la deuxième moitié de la Révolution, et analysera les acteurs et mécanismes de ces réactions. Enfin, et surtout, il mettra en évidence l'importance cruciale du concept de « réaction » dans l'interprétation de l'histoire politique de la région.

La formation des factions et l'héritage de la haine : jacobins et anti-jacobins

11 La série de réactions qui toucha la région après Thermidor fut en grande partie une continuation des luttes de faction qui sévissaient depuis les premières années de la Révolution. La violence émanant des factions était en effet présente dès le début de la Révolution dans la plupart des communes de la région. Cette violence était à la fois individuelle et collective, impliquant des meurtres isolés et l'action des foules. Ce fut pendant les premières années de la Révolution que se formèrent les caractéristiques des réactions qui allaient suivre: le changement radical de pouvoir d'une faction à l'autre. Et ces premières années promurent la vengeance comme facteur déterminant 
de la politique locale - vengeance envers les individus et les groupes. Cette violence permit de cristalliser les factions en groupes de plus en plus antagonistes, dont les conflits perdurèrent jusqu'à la fin de la Révolution. Ainsi, pour bien comprendre la violence des années suivant 1794, il faut nécessairement remonter aux années précédentes pour analyser, même succinctement, les origines révolutionnaires du conflit politique.

des deux partis constitua le leitmotiv de la politique locale tout au long de la décennie révolutionnaire. Ce fut un combat précoce et passionné. Dès le printemps 1789, le calme relatif dont jouissait la Provence au XVIII ${ }^{\mathrm{e}}$ siècle fut interrompu par une série d'émeutes rurales et urbaines, d'incidents de violence populaire, de faits de lynchage et de décapitations, ainsi que de violentes confrontations entre les forces de l'ancien et du nouveau régime ${ }^{12}$. La vie politique régionale devint rapidement polarisée. En Arles, pour ne citer qu'un exemple, les divisions, déjà apparentes pendant les élections aux États généraux, gagnèrent en intensité et en violence à chaque phase de la Révolution. Ces divisions étaient perceptibles dans le conflit bien connu qui opposait les chiffonistes et les monnaidiers, chaque groupe ayant un quartier et des caractéristiques socio-économiques propres. Les monnaidiers, issus en majorité du monde artisanal $(23 \%)$ et des professions maritimes (11\%), habitaient souvent les quartiers les plus pauvres de la Monnaie et de Trinquetaille, tandis que les chiffonistes, d'origine sociale généralement plus élevée, se recrutaient principalement parmi les bourgeois et les propriétaires (18,6\%), les professions juridiques $(10,4 \%)$ et parfois la petite et grande noblesse ${ }^{13}$. En 1791 déjà, le commissaire du roi remarquait le caractère très personnalisé de ce conflit: «Depuis l'époque de la révolution, peu de villes ont offert le spectacle de deux partis aussi formellement opposés, aussi profondément ulcérés. Tous les deux n'ont pas leur cocarde et leur drapeau, mais les haines sont si violentes, les menaces, les provocations ont été si fréquentes, que les meneurs et les menés ne se trompent jamais sur les individus de chaque parti.» En effet, et le plus souvent lors de dépositions effectuées devant les autorités judiciaires au cours de la décennie, des témoins purent identifier leurs adversaires - généralement issus de la faction opposée - par le nom, le prénom, la profession et même l'adresse. De telles familiarités sociales et divisions politiques étaient également courantes dans d'autres communes, petites ou grandes, des Bouches-du-Rhône ${ }^{14}$.

14 Les sociétés populaires jouèrent un rôle crucial dans les conflits politiques de la région. À la fin de 1790, la plupart des communes importantes des Bouches-du-Rhône étaient dotées d'au moins un club, parfois de deux ou plus, dont les membres s'appelaient généralement clubistes, et non pas Jacobins, malgré leur affiliation généralisée à la société mère de Paris ${ }^{15}$. À la fin de l'an II, 85 \% des communes des Bouches-du-Rhône et, soulignons-le, $91 \%$ de celles du Vaucluse - comptaient une société populaire. Ces clubs, d'une composition sociale variée, essentiellement artisanale, établirent un réseau élaboré d'alliances et de correspondances politiquement puissantes. Défenseurs de la constitution et de la Révolution même, ces sociétés populaires jouèrent très tôt un rôle actif dans leurs communes, organisant fêtes, éducation civique, assistance aux pauvres, et fonctionnant tels des groupes de pression locaux. La plupart de ces sociétés exerçaient une stricte surveillance sur les autorités locales constituées ainsi que sur les individus considérés comme « ennemis du bien public » et de la Révolution ${ }^{16}$. La plupart des clubs, notamment ceux des grandes communes d'Aix, Arles, Marseille, Tarascon et Salon, prétendant détenir le monopole du patriotisme et faisant, à ce titre, des 
distinctions entre les «bons » et les «faux » patriotes, imposaient par-là même une politique d'exclusion envers ceux qui transgressaient leurs idéaux révolutionnaires.

La prolifération du réseau des clubs jacobins dans les Bouches-du-Rhône comme ailleurs, leur organisation et leur engagement idéologique contribuèrent largement à la polarisation croissante de la politique locale. Ces confrontations se manifestaient tout particulièrement en période d'élection. Pendant toute la décennie révolutionnaire, au début comme à la fin, les élections représentaient le principal accès au pouvoir local. Dans les assemblées primaires et électorales, la compétition pour les postes administratifs et juridiques, que ce soit au niveau municipal, départemental ou national, était souvent conflictuelle, voire violente ${ }^{17}$. Les clubistes locaux se montraient particulièrement férus de politique électorale, déployant avec efficacité des aptitudes logistiques et de mobilisation politique.

Dans les premières années de la Révolution, de 1790 à 1792, les clubistes des principales communes assurèrent leur emprise sur les charges publiques telles que maires, procureurs syndics, administrateurs, juges de paix et officiers de la garde nationale, et obtinrent une forte représentation parmi les électeurs des assemblées électorales, sans oublier les députés élus aux assemblées nationales. Dès les premières élections municipales de 1790, certains membres des clubs locaux tenaient une place éminente parmi les électeurs, les membres du bureau et les élus, emportant au moins un tiers des offices municipaux à Aix, Arles, Marseille, Salon et Tarascon et représentant environ $40 \%$ des électeurs de ces villes ${ }^{18}$.

17 Après l'assemblée électorale d'août-septembre 1791, les clubistes non seulement dominaient dans ces villes, mais contrôlaient aussi l'administration du département des Bouches-du-Rhône, dont les élus étaient des membres importants de leurs clubs respectifs, certains d'entre eux anciens ou futurs présidents. Les élections de l'été 1792 constituèrent l'apogée du succès électoral des clubistes locaux. Pas moins de $87 \%$ du personnel municipal à Aix, $82 \%$ à Marseille - les deux principales villes des Bouchesdu-Rhône - et deux tiers du directoire du département étaient issus des sociétés populaires. Beaucoup de ces élections commencées en 1790 - à Aubagne, Allauch, Barbentane, Eygalières, Eyragues, Jouques et Mazargues, entre autres - furent agitées, requérant parfois le recours aux gardes nationaux locaux ou aux troupes régulières, afin de maintenir l'ordre entre les partis ${ }^{19}$. Ainsi que l'écrivit, en décembre 1791, le directoire du district de Tarascon à propos du récent conflit de Barbentane: "Les troubles de Barbentane proviennent du choc des deux partis. Le club et le restant des citoyens. $»^{20}$

La lutte des factions et la violence populaire, 1790-1793

Ces années de pouvoir jacobin grandissant furent marquées par une violence toujours plus âpre entre clubistes et non clubistes dans presque toutes les grandes communes des Bouches-du-Rhône en 1790 et $1791^{21}$. Des groupes de patriotes attaquèrent les hommes, les institutions et les symboles de l'Ancien Régime, ainsi que ceux qui étaient perçus comme des agents du despotisme, de l'aristocratie et de la contre-révolution. Surtout, la société politique de Marseille, sans doute l'une des plus puissantes de province, s'attribua le rôle de protectrice de la Constitution, et même de la Révolution. Agissant de sa propre initiative ou par le biais de son vaste réseau de clubs régionaux, le club de Marseille, comme la ville elle-même, influença beaucoup - certains diront même domina - la politique de la région. En effet, la ville de Marseille exerçait un rôle prépondérant sur l'ensemble du département, voire de la région, pendant toute la 
décennie révolutionnaire. Bienfaisante pour certains, fatale pour d'autres, cette influence dans le Midi était souvent comparée à celle de Paris sur la France ${ }^{22}$. La Société des Amis de la Constitution de Marseille intervint avec énergie dans la politique municipale, organisa des expéditions à Aix, Arles et, de manière spectaculaire, à Paris, protégea les patriotes menacés et envoya des commissaires - les missionnaires patriotiques - pour fonder des clubs et diffuser l'idéologie jacobine ${ }^{23}$. L'exemple de Marseille, s'il ne fut jamais égalé en intensité et en influence, fut imité par d'autres clubs des Bouches-du-Rhône, notamment celui des Antipolitiques d'Aix. La radicalisation politique du département, dans lequel le rôle du club était primordial, fut exacerbée par les dangers, réels ou imaginaires, autant que par la résistance opposée, selon les clubistes, à la Révolution. Les opposants des clubs les accusaient d'arrogance, de tyrannie, de brutalité, d'exclusivisme, et refusaient qu'ils s'arrogent le monopole du titre de " patriote ». En effet, l'utilisation large et souvent stratégique de termes comme « aristocrate » et " contre-révolutionnaire » contribua à la polarisation politique de la période ${ }^{24}$.

Pendant le printemps et l'été 1792, les campagnes et villes de Provence furent touchées par une violence extrême $e^{25}$. Dans les Bouches-du-Rhône, les problèmes d'ordre public s'aggravèrent lorsque des foules d'hommes et de femmes s'attaquèrent aux personnes et aux propriétés. Outre les actes de nature anti-seigneuriale et anti-nobiliaire, dont le pillage et la destruction de plusieurs châteaux et autres signes de l'Ancien Régime, certains membres des sociétés populaires organisèrent une campagne énergique contre leurs ennemis désignés, qu'ils soient "modérés ", "aristocrates ", «contrerévolutionnaires » ou "riches». Cette campagne s'accompagna d'actes d'intimidation et de violence - voies de fait, contributions forcées, arrestations arbitraires, pillages, incendies et assassinats. De nombreuses communes devinrent le théâtre d'exécutions sommaires et publiques orchestrées par des "pendeurs»: à Marseille, Aubagne, Pertuis, Tarascon, Auriol, en Arles et ailleurs, le lynchage des «ennemis de la patrie » était perpétré par des foules animées par la vengeance ou la peur du complot, chantant souvent Ça Ira, et parfois encouragées par certains membres des clubs jacobins ${ }^{26}$.

Plusieurs membres de la garde nationale, loin d'empêcher ces actes, en furent euxmêmes les complices, voire les instigateurs; de même, nombre d'administrateurs ne prirent pas les mesures nécessaires à l'arrêt des violences. En Arles, où la violence entre les factions chiffoniste et monnaidière divisait la ville depuis 1790 , les monnaidiers, de retour au pouvoir au printemps 1792, se vengèrent de leurs adversaires par une série de meurtres, bastonnades et pillages. Cette violence s'intensifia pendant l'été lorsqu'un prétendu « comité des sabres », composé de plusieurs membres de la société populaire, organisa au moins onze meurtres de chiffonistes, parmi lesquels l'exécution sommaire d'un homme tiré des prisons et massacré dans la rue, une forme de violence alors fréquemment pratiquée. Souvent actrices des luttes politiques en Arles, comme ailleurs, les femmes n'étaient pas épargnées par la violence des factions. En septembre 1792, dix-huit Arlésiennes, toutes épouses ou veuves de membres importants de la faction chiffonière, firent l'objet d'une humiliation publique, ayant été déshabillées et promenées sur des ânes à travers la ville, tout en étant fouettées et maltraitées ${ }^{27}$. Des actes similaires de violence eurent lieu dans d'autres départements de Provence, notamment dans le Vaucluse et le Var. À Toulon par exemple, de juillet à septembre, les foules assassinèrent au moins vingt personnes, y compris plusieurs membres des administrations du département et du district; la plupart des personnes assassinées étaient des adversaires connus des Jacobins toulonnais ${ }^{28}$. Les autorités constituées ainsi 
que de nombreuses sociétés populaires et les membres des sections exprimèrent horreur et indignation face aux attaques continuelles et généralisées contre les personnes et les propriétés. Ils firent des proclamations et prirent des arrêtés en faveur de la tranquillité publique et, en octobre, dans une tentative pour maintenir l'ordre et éviter la violence populaire, les sections de Marseille créèrent un Tribunal populaire ayant compétence à juger de manière non-partisane les délits commis contre les personnes et les propriétés ainsi que nombre de crimes politiques ${ }^{29}$.

Ces vagues de violence comptèrent parmi leurs victimes - sorties de prison et battues à mort ou lynchées - des membres du parti opposé ainsi que de leur famille ; sans aucun doute, sous couvert de suspicion de contre-révolution ou de manque de patriotisme, des animosités personnelles entretenaient aussi un héritage de haine toujours plus douloureux.

Pendant l'hiver 1792 et l'année 1793, les incidents de violence populaire continuèrent, souvent à l'incitation et avec l'accord des clubs locaux ${ }^{30}$. À Salon, en février 1793, des commissaires de la puissante société populaire de Marseille, assistés de certains membres de la commune, entrèrent dans la ville avec une force armée et abusèrent de leur pouvoir, organisant des visites domiciliaires et des arrestations arbitraires, imposant des contributions forcées et assassinant quatre citoyens ${ }^{31}$. À Aix, certains membres des Antipolitiques sont accusés d'avoir appelé à forcer les prisons à plusieurs reprises, et au cours du premier trimestre 1793, huit prisonniers en sont sortis et tués, généralement par pendaison, sous le prétexte, si l'on en croit la municipalité d'Aix, que « la justice criminelle était tout à la fois trop lente dans sa marche et trop douce dans ses peines $\|^{32}$. Les autorités constituées des Bouches-du-Rhône et de la Provence en général, ainsi qu'un nombre croissant de citoyens, s'indignèrent de ces attaques contre les personnes et les propriétés, attaques qui, selon certains, discréditaient la Révolution tout entière. Demandant l'aide de la force armée locale, la municipalité d'Arles écrivit au commandant de la garde nationale : «Il est temps que les scènes aussi barbares que déshonorantes pour ceux qui en sont les auteurs aient enfin un terme $»^{33}$. Presque toutes les autorités locales invoquaient la nécessité de la loi comme source d'ordre public et comme rempart contre la violence populaire. Si certains membres des clubs partageaient cette condamnation générale de la violence qui ravageait la région, le sentiment dominant dans les sections de Marseille et d'Aix se faisait de plus en plus hostile aux Jacobins, tenus pour responsables de la plupart de ces excès. À Marseille, la peur de la violence populaire, à laquelle s'ajoutait la détermination à protéger la liberté individuelle, aboutit, le 1er octobre 1792, à la création de deux tribunaux populaires par les sections de la ville et au sein même du club. Cette opération institutionnalisait une forme de justice populaire dont le but était d'administrer une prompte justice aux auteurs et complices de complots contre-révolutionnaires, tout autant que de punir les personnes coupables d'actes criminels et, ainsi, de désamorcer la vengeance populaire $^{34}$.

La révolte fédéraliste et la Terreur

23 Dans le département des Bouches-du-Rhône, la révolte fédéraliste et la Terreur cristallisèrent le conflit entre les partis. D'une rare intensité et d'une violence exceptionnelle, ces deux périodes s'étalant du printemps 1793 à la fin de l'été 1794 constituèrent des phases distinctes dans la lutte tenace qui opposait les clubistes et leurs adversaires plus modérés - lutte qui engloba alors une portion plus importante que jamais de la population rurale et urbaine. Aux yeux de maints contemporains, la 
révolte fédéraliste constitua une réaction politique, une réaction contre les excès attribués aux clubistes de l'été 1792 au printemps 1793, et contre les actions d'une Convention largement dominée par les Montagnards à Paris ${ }^{35}$. De même, la Terreur - ou plus précisément les différentes périodes de la Terreur qui ponctuèrent l'année 1793-1794 - fut en grande partie, au moins au niveau local, une réponse à la révolte fédéraliste. Quelles qu'aient été les variantes nationales ou régionales de ces périodes, le département des Bouches-du-Rhône assista à un conflit de factions dont la plupart des membres - bien que rejoints par de nouveaux protagonistes - avaient déjà connu une expérience révolutionnaire.

De manière significative pour le reste de l'histoire politique de la région, ces mois intensifièrent et élargirent la guerre des factions. Non pas que ces phases puissent être réduites à de simples conflits de factions ou de vendetta privée, mais il ne fait aucun doute que ces périodes de crise offrirent d'abondants prétextes aux règlements de comptes, qu'ils soient collectifs ou individuels. L'idéologie joua certainement un rôle dont l'importance évolua avec le temps et les circonstances, variant en contenu et en intensité selon les personnes et les lieux. Mais il n'en demeure pas moins certain qu'une des conséquences de ces périodes fut d'exacerber et d'étendre l'héritage des haines accumulées depuis les premières années de la Révolution. La révolte fédéraliste et la Terreur, en effet, virent l'arrestation, l'émigration et l'exécution de centaines d'hommes, de femmes et d'enfants, la confiscation et la vente des propriétés privées, la fuite de milliers d'autres individus, tous victimes de dénonciations, fausses ou réelles, et bien souvent des circonstances politiques.

La révolte fédéraliste - ou, plus précisément, le mouvement des sections - dans le département des Bouches-du-Rhône pendant le printemps et l'été 1793 fut un produit de facteurs nationaux et locaux et comme ailleurs, dans d'autres départements, notamment à Lyon et Bordeaux, le mouvement prit naissance et rayonna à partir des grandes villes de la région: Aix et surtout Marseille ${ }^{36}$. À partir du printemps 1793, la révolte se manifesta par la création d'assemblées sectionnaires dans les grandes et petites communes du département, tantôt à l'initiative des grandes villes, tantôt à l'instigation des communes elles-mêmes.

Sur le plan local, la réaction contre ce que les sectionnaires condamnaient comme les excès du printemps et de l'été 1792 est essentielle pour comprendre la nature du mouvement. Devant les sections et leurs comités de surveillance, et surtout devant le Tribunal populaire, les victimes dénonçaient les souffrances qu'elles avaient subies: arrestations arbitraires, contributions forcées, désarmements, destruction des propriétés, et toutes les méthodes d'intimidation et les violences perpétrées par certains membres des sociétés populaires au nom de l'intérêt de la nation. Comme en témoigne l'arrêté rédigé par la section 7 de Marseille en mai 1793 : "Il est impossible que la République puisse subsister et que nous ne soyons pas au contraire livrés à tous les excès de l'anarchie la plus effrénée $»^{37}$. Et le département des Bouches-du-Rhône de poursuivre peu de temps après: "C'est l'anarchie, les vexations, les brigandages qui ont porté le peuple de ce département à se lever tout entier pour remédier à ses maux, faire respecter les personnes et les propriétés et maintenir la République une et indivisible $\aleph^{38}$. L'idéologie fédéraliste telle qu'elle était exprimée section après section dans les différentes communes du département exaltait le règne de la loi par opposition à la violation des lois ; elle proclamait des principes de paix, d'unité, de fraternité et de soumission la plus entière aux lois et lançait une guerre aux factieux, agitateurs, 
intrigants, aristocrates et royalistes ; ils jurèrent enfin de maintenir - jusqu'à la mort la République une et indivisible.

Si la plupart de ces conflits étaient locaux, impliquant souvent des membres des deux factions dont l'expérience politique remontait aux premières années de la Révolution, le mouvement était profondément anti-parisien, profondément anti-montagnard. Les

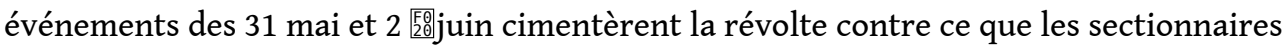
locaux décrivaient comme l'anarchie de la politique montagnarde, locale comme nationale ${ }^{39}$. Au niveau local, un trait significatif du mouvement dans presque toutes les communes fut la fermeture systématique des anciennes sociétés populaires, souvent accompagnée de la destruction de leurs lieux de réunion, ou plus simplement de leur appropriation, et l'arrestation de certains de leurs membres. Des centaines d'adhérents de ces sociétés populaires locales réclamèrent par la suite des indemnités pour leur fuite forcée, leur emprisonnement et les vexations subies des mains des fédéralistes, souvent les mêmes personnes avec lesquelles elles avaient livré un combat politique au début de la Révolution. Les familles des clubistes ne furent pas plus épargnées : parmi les personnes demandant à être indemnisées figuraient un nombre important de femmes, d'épouses et de filles, parfois de veuves, jugées coupables par association ou soupçonnées d'implication dans la politique locale ${ }^{40}$.

Les membres des assemblées sectionnaires des grandes et petites villes, ainsi que ceux des différentes municipalités, districts et départements, formaient globalement un groupe différent de celui de leurs adversaires clubistes. Si certains sectionnaires étaient en fait d'anciens membres des sociétés populaires locales - une minorité relativement petite - la plupart n'avaient jamais fait partie des clubs. D'un point de vue politique, d'après leurs expériences administratives antérieures, ils formaient un mélange d'ancien et de nouveau. Dans certaines communes comme Aubagne, Salon, Aix et Arles, certains membres de l'Ancien Régime occupèrent des postes administratifs pendant l'été 1793 , toutefois en proportions variables : à Salon $7 \%$ et en Arles $17 \%$ des officiers municipaux avaient été administrateurs avant ou pendant 1789, alors qu'à Aubagne 41 $\%$ et à Aix $48 \%$ des officiers municipaux sous la révolte fédéraliste provenaient de l'Ancien Régime ${ }^{41}$. En outre, certains de ceux qui occupaient des postes municipaux dans ces villes en 1790 et 1791 faisaient partie de l'élite fédéraliste : le personnel du département, les districts, les municipalités ainsi que les présidents et secrétaires des sections, notamment à Aix et Marseille, et le comité central de Marseille ${ }^{42}$.

La majorité des fédéralistes des principales villes des Bouches-du-Rhône n'avaient jamais rempli de charges publiques pendant la Révolution. La plupart de ces hommes nouveaux représentaient l'élite sociale et financière de leurs communes respectives, avec un nombre important de négociants, bourgeois, notaires et propriétaires, généralement plus riches que leurs adversaires jacobins. À Aix par exemple, un tiers d'entre eux était issu de l'élite juridique ou médicale de la ville. La municipalité fédéraliste d'Arles, quant à elle, comprenait des hommes plus riches que ceux de toutes les administrations qui s'étaient succédées depuis la Révolution ${ }^{43}$. La révolte fédéraliste dans les Bouches-du-Rhône représenta dans une certaine mesure la revanche des propriétaires contre la menace de la domination et de l'extrémisme jacobins.

Cela ne veut pas dire que ces hommes nouveaux étaient forcément étrangers à la politique locale. Au contraire. Bon nombre d'entre eux avaient participé à des élections, assisté à des assemblées sectionnaires ou s'étaient impliqués dans la politique de faction dès les premières années de la Révolution. L'exemple d'Arles est 
particulièrement frappant en matière de continuité politique : au moins $60 \%$ du personnel fédéraliste de la ville, dont celui de la municipalité, du district et les juges de paix, appartenait au parti chiffoniste qui, avec les monnaidiers, sa faction rivale, divisait la politique municipale depuis le début de la Révolution.

Le mouvement fédéraliste dans les Bouches-du-Rhône a été considéré par certains contemporains comme la première réaction, et cela, d'une certaine manière, se justifie. L'épisode fédéraliste dans les Bouches-du-Rhône fut une réaction à la fois politique, idéologique et sociale, une réponse des éléments plus modérés ou conservateurs de la société provençale à ce qu'ils percevaient comme l'extrémisme jacobin. Les fédéralistes eux-mêmes étaient très largement républicains, mais beaucoup résolument anticlubistes, comme en témoignent amplement leurs adresses, pétitions, délibérations et discours. Ils conservèrent leur engagement républicain, du moins envers leur propre vision de la République, une République une et indivisible, purgée de l'extrémisme qu'ils associaient aux clubs et à la domination montagnarde. En un mot, les fédéralistes n'étaient pas fondamentalement contre-révolutionnaires, ni royalistes, même si leurs adversaires jacobins les considéraient comme tels.

De fait, l'épisode fédéraliste, surtout dans ses manifestations locales, provoqua à son tour de fortes représailles de la part des clubistes et de leurs partisans. Cette réponse prit une ampleur pluridimensionnelle : justifiée et motivée par l'idéologie, elle avait été mise en œuvre par des personnalités nationales et locales, orchestrée par des institutions nationales et locales comme le comité de surveillance, les tribunaux révolutionnaires, les commissions militaires et exceptionnelles et les sociétés populaires, et, souvent, animée par la politique de faction. On ne saurait assez insister sur le fait que peu d'épisodes de la Révolution eurent autant de conséquences sur l'histoire du département et de la région - et sur la politique des réactions - que la révolte fédéraliste et la Terreur.

Après l'échec du mouvement fédéraliste et la défaite de l'armée départementale par les troupes républicaines en août 1793 , la période de la Terreur vit le retour massif des clubistes à des positions de pouvoir dans la politique locale. Les membres des sociétés populaires, dont beaucoup occupaient une position en vue dans leur club et s'étaient impliqués dans des luttes politiques depuis le début de la Révolution, allèrent occuper la majorité des postes des institutions de la Terreur dans leurs communautés et leurs départements : dans les comités de surveillance, les tribunaux révolutionnaires et les autorités constituées au niveau des municipalités, des districts et du département. Contrairement à la plupart des fédéralistes, les hommes qui occupèrent des postes publics de l'automne 1793 à la fin de l'été 1794 affichaient un profil socio-économique radicalement opposé à celui de leurs adversaires fédéralistes, étant majoritairement artisans et cultivateurs, et nettement moins riches ${ }^{44}$. Les historiens prenant le parti d'interpréter la Terreur en termes de classe trouveront de quoi étayer cette théorie parmi les documents fiscaux, les actes notariés et les recensements de l'époque. Mais, tout aussi important, surtout du point de vue de la politique de faction, est le passé politique des terroristes mêmes. Beaucoup avaient occupé des positions au sein du pouvoir local depuis 1790 , en conflit avec des opposants connus et bien identifiés, et un nombre significatif de ces clubistes avaient été persécutés par les fédéralistes dénoncés, forcés de fuir, emprisonnés, blessés ou exécutés - comme en témoigne la liste, probablement surestimée, des indemnisés ${ }^{45}$. 

ects une phase dans le long conflit qui opposa les factions. Même si les représentants en mission envoyés dans la région, aussi différents en termes de personnalité et d'approche que Fréron, Barras et Maignet, contribuèrent largement au caractère de la Terreur, chacun fut impressionné, voire choqué, par la force des rivalités entre les factions locales. Ces rivalités, intestines et féroces, furent exacerbées par la Terreur, s'avérant en effet plus envahissantes et plus sanglantes qu'auparavant. Le tribunal révolutionnaire et la commission militaire jugèrent à eux deux environ 1200 personnes et en exécutèrent 478 , en majorité pour cause de fédéralisme ${ }^{51}$. Mais l'impact de la Terreur dans les Bouches-du-Rhône, ou ailleurs, ne se mesure pas uniquement en nombre d'exécutions : en moins d'un an, de septembre 1793 à la fin de juillet 1794, la Terreur toucha des milliers de résidents par ses émigrations forcées, ses arrestations (parfois de familles entières, d'amis et de proches) et ses confiscations de propriétés. Les terroristes avançaient qu'ils défendaient la République autant qu'ils punissaient leurs ennemis politiques. Si elle fut nationale par son langage et ses institutions, la Terreur dans les Bouches-du-Rhône demeura largement locale dans ses perspectives et dans son essence : ses participants appartenaient à des communautés locales, et étaient souvent marqués politiquement. Mais la violence institutionnalisée 
de la Terreur n'en engendra pas moins un héritage de haine, héritage qui aidera à expliquer l'ampleur des réactions politiques locales à venir.

La réaction de l'an III

37 La politique de l'an III se développa en grande partie en réaction à la Terreur. Comme toutes les autres réactions passées et à venir, elle s'inscrivait dans une lutte plus vaste et plus longue entre deux groupes de personnes impliquées dans l'expérience révolutionnaire. Si la guillotine fut le symbole de la justice sous la Terreur, le poignard pourrait bien avoir été celui de la réaction. L'arrivée d'un nouveau groupe de représentants en mission dans la région après Thermidor an II, la libération des suspects, le retour de ceux qui avaient été forcés de se cacher ou d'émigrer, l'épuration et parfois la fermeture des sociétés populaires, le changement des autorités constituées et la nomination aux postes publics des modérés et anciens fédéralistes - tout cela contribua à provoquer une transformation profonde du climat politique, un climat caractérisé par la vengeance ${ }^{52}$. Pendant le printemps et l'été 1795 , des actes de violence individuels et des massacres collectifs dans les prisons des Bouches-du-Rhône - à Aix, Tarascon et Marseille - dirigés essentiellement contre des anciens terroristes et leurs familles, valurent à la région sa réputation de l'une des contrées les plus affectées par la réaction de l'an III.

La responsabilité des autorités constituées ainsi que des représentants eux-mêmes, tels Paul Cadroy et Maximin Isnard, dans les violences qu'ils incitèrent ou laissèrent faire demeure sujet à vif débat pour cette période et les suivantes ${ }^{53}$. Le langage de ces autorités dans leurs proclamations, adresses et correspondance était viscéralement antiterroriste. Il est clair que le caractère véhément et répétitif du langage antiterroriste dans les proclamations et la correspondance officielle n'avait pas pour but de créer un climat d'apaisement ${ }^{54}$. Les anciens terroristes étaient stigmatisés comme des êtres immoraux, corrompus, profiteurs et meurtriers, déshumanisés comme des tigres, des serpents, des monstres et autres bêtes sauvages, catalogués comme des cannibales naturellement violents, des buveurs de sang dont l'action néfaste avait presque détruit la République sous une forêt d'échafauds ${ }^{55}$. Les termes "intrigants" et "faux patriotes", auparavant appliqués par les clubistes à leurs adversaires, étaient maintenant utilisés contre les clubistes eux-mêmes! Le vocabulaire des discours de l'an III semble inspiré de celui utilisé au printemps 1793 contre les membres des sociétés populaires, et faisait partie du répertoire d'injures antijacobines qui ne cessait de s'enrichir depuis les débuts de la Révolution ${ }^{56}$. Il n'y avait à cela rien d'étonnant, les hommes rédigeant ces discours étant en grande partie les mêmes.

La violence engendra la violence. Les victimes de la Terreur devinrent souvent les bourreaux de la réaction, et les oppresseurs endossèrent le rôle d'opprimés. Au printemps 1795 dans les Bouches-du-Rhône, l'attaque contre les anciens jacobins et leurs familles atteignit des proportions endémiques: «Presque chaque commune de ce département, écrit alors Pellissier, député des Bouches-du-Rhône, devint le théâtre de quelque vengeance particulière ${ }^{57}$. Dans la majorité des cas, la violence antiterroriste était une affaire hautement localisée, menée par arrondissements, quartiers et rues, par des personnes qui se connaissaient très souvent par leur nom, leur profession et même leur adresse ${ }^{58}$. Dans les célèbres massacres des prisons de Tarascon et d'Aix, ainsi que du Fort Saint-Jean à Marseille, tous préparés à l'avance, certaines personnes des communes voisines allèrent gonfler les rangs d'autres «égorgeurs" pour assassiner leurs victimes soigneusement sélectionnées ${ }^{59}$. 
40 lors de transferts en prison comme à Salon et Aubagne, jusqu'aux massacres du Fort Saint-Jean à Marseille, et ceux d'Aix et de Tarascon, était souvent exécutée par des groupes d'hommes opérant ensemble ${ }^{60}$. Pas moins de 250 personnes sont censées avoir participé à deux massacres dans les prisons de Tarascon, bien que seulement 41 d'entre elles furent ultérieurement accusées. Dans les prisons du Fort Saint-Jean, également, un total de 16 personnes furent accusées d'avoir participé au massacre de prisonniers le plus sanglant du Midi. Et la bande d'Aubagne, composée d'au moins 61 membres, opérant dans le district de Marseille, fut responsable du meurtre d'au moins 17 personnes, toutes impliquées dans la Terreur pendant les mois de messidor, prairial et thermidor an $\mathrm{III}^{61}$. Alors que cette rage meurtrière était dirigée contre une cible bien identifiée, le climat politique, comme très souvent dans de tels moments de crise, favorisait les règlements de compte de toutes sortes, personnels et professionnels. Contrairement à la Terreur de l'an II, la réaction de l'an III se caractérisa par une violence populaire et personnalisée, à la fois individuelle et collective.

Bien souvent, la violence de l'an III, tout comme la violence de toute la décennie révolutionnaire, avait des antécédents et s'inscrivait dans la continuité des luttes révolutionnaires. Ceux qui participaient à ces meurtres, en effet, étaient parfois des émigrés, des personnes qui avaient été emprisonnées sous la Terreur, des proches ou amis des victimes, sinon des victimes mêmes. Augustin Pelard, pour ne citer qu'un exemple parmi beaucoup d'autres, impliqué dans le massacre du Fort Saint-Jean, avait été emprisonné pendant la Terreur, ainsi que son oncle ${ }^{62}$. Et parmi les treize personnes qui provenaient d'un attroupement ayant assassiné trois individus - un père et ses deux fils - le 3 messidor an III près d'Aubagne, dix figuraient sur la liste des émigrés ${ }^{63}$.

Les autorités locales comme le procureur général syndic du département, l'accusateur public auprès du tribunal criminel, ainsi que les représentants du peuple Chambon et Isnard, se déclarèrent eux-mêmes choqués par l'étendue de la violence, et ordonnèrent que des investigations sur ces assassinats fussent menées par les juges de paix et les tribunaux locaux ${ }^{64}$. La sincérité de ces professions et l'assiduité de leurs investigations, doivent rester un sujet de spéculation plutôt qu'une démonstration. Et il est vrai que pour certains, tel le procureur syndic du district de Marseille, la violence était regrettable, mais justifiée par l'énormité des crimes commis par les anciens terroristes ou encore par des actions redoutées, notamment le fameux soulèvement de Toulon au début de prairial an III, provoquant des ondes de choc dans toute la région : " Nous avons à gémir sur les actes de violence qui se sont commis !... Sans doute... Mais si les scélérats, les terroristes et les buveurs de sang, qui se voient à l'agonie, ne levaient pas une tête aussi altière et ne cherchaient pas, sous les prétextes les plus insidieux, à nous agiter en tout sens, pour nous désunir et nous perdre, le citoyen paisible, tranquille et soumis aux lois, ne se verrait pas forcé de purger le sol de la république de ses ennemis les plus déclarés. ${ }^{65}$ Dans les Bouches-du-Rhône, comme dans d'autres départements, un climat de vengeance prédominait, ainsi qu'un désir de punir les anciens terroristes, par des moyens légaux ou non, pour leur conduite de l'année passée. En effet, de nombreuses autorités constituées, tout en condamnant la violence, citaient la lenteur des jugements de ces anciens terroristes par le tribunal criminel comme un facteur majeur d'explication de ces assassinats. Pour beaucoup, la lenteur de

Annales historiques de la Révolution française, 345 | juillet-septembre 2006 
la procédure judiciaire leur semblait une ironie cruelle et une provocation ouverte face au caractère expéditif et si souvent dénoncé de la justice révolutionnaire.

Pendant le printemps, l'été et l'automne 1795, dans les Bouches-du-Rhône, des victimes d'actes de violence, d'arrestations arbitraires, de contributions forcées, de préjudice matériel et d'assassinats envoyèrent des déclarations aux juges de paix locaux et aux comités de surveillance. Certaines de ces allégations concernaient des crimes remontant aussi loin qu'à l'été 1792 - témoins de la continuité des conflits, des personnalités et des problèmes encore irrésolus qui ravageaient la région ${ }^{66}$. L'affaire de Salon - dont l'instruction avait commencé sous la révolte fédéraliste - fut rouverte en messidor III et eut pour résultat l'exécution de six personnes, dont l'ancien maire de la ville, ainsi que l'emprisonnement de l'ancien président du département à l'époque de la Terreur ${ }^{67}$. Et d'autres, également, furent exécutés pour des actes tels que des pendaisons ou le meurtre de l'éminent Jacobin marseillais François Isoard, exécuté le 3 vendémiaire IV en présence d'une foule substantielle venue assister à son exécution ${ }^{68}$.

Mais une violence d'un type plus anarchique, une violence motivée par la vengeance personnelle, perdura dans le département et la région au cours des derniers mois de 1795. Le nombre de ces meurtres et persécutions est incalculable malgré les efforts, entrepris essentiellement en l'an VI, de quantification. Les divers «tableaux des assassinats » ébauchés par les municipalités, même si l'on tient compte d'une certain degré d'exagération ou de distorsion, témoignent du fort degré de violence et de l'immense degré d'antiterrorisme qui sévissait librement dans le département. Les nombreux incidents - impliquant souvent coups, blessures, mutilations, dévastations de propriétés privées, exil forcé et meurtres, entre autres outrages - exercés contre les " patriotes » et les « républicains " par les « royalistes » et la «faction royale » restent un signe et un symptôme de l'impact de la Terreur sur les communes, petites ou grandes ${ }^{69}$.

Si le terme "réaction", dans son sens politique de rejet des hommes et des institutions de la Terreur, entra dans le langage courant des Parisiens dans les mois suivant le 9 Thermidor, son utilisation en province fut plus tardive ${ }^{70}$. Au début de l'an IV, il s'était imposé dans le lexique politique, utilisé notamment par des autorités constituées, des représentants en mission et des députés de diverses tendances politiques pour décrire une réalité incontestée de politique locale. Toutefois, l'épithète "royaliste » allait devenir indissociablement liée à la réaction dans les écrits des anciens jacobins et de leurs partisans. Marie-Joseph Chénier, pour sa part, dans son Rapport fait à la Convention nationale au nom des Comités de Salut public et de Sûreté générale lors de la séance du 29 vendémiaire an IV, appliqua cette notion tout particulièrement au département des Bouches-du-Rhône ${ }^{71}$. Le langage de l'époque associa plus que jamais la réaction au royalisme et à la contre-révolution, même si la grande majorité des fonctionnaires de l'an III s'avéraient moins antirépublicains qu'antiterroristes, à en juger par leur passé politique et l'idéologie qu'ils professaient.

$\mathrm{Au}$ cours des assemblées primaires et des assemblées électorales qui se déroulèrent en fructidor an III et vendémiaire an IV, les modérés, conservateurs ou réactionnaires, qui comptaient d'anciens fédéralistes ou émigrés, consolidèrent leur contrôle des administrations municipale et départementale, ainsi que judiciaire, mais furent, pour une grande part, exclus de toute charge publique par la loi du 3 brumaire. En effet, à en juger par les procès-verbaux des assemblées primaires et électorales, de nombreux participants aux élections, ainsi que ceux qui furent élus, appartenaient à une des 
factions depuis le début de la Révolution ${ }^{72}$. Le choix des députés au corps législatif, qui comprenait des conventionnels thermidoriens d'importance comme Boissy d'Anglas, Durand-Maillane et Cadroy lui-même, ainsi que des anciens fédéralistes comme l'Aixois Siméon et Jourdan d'Aubagne, confirma l'atmosphère conservatrice qui flottait sur le département en général. L'acceptation généralisée de la Constitution de 1795 annonça pour beaucoup le retour à la stabilité politique, l'arrêt des conflits et des dissensions, l'établissement du règne de la loi, le rejet de la Terreur, la répression des factions, et, surtout, la fin des réactions.

La Convention nationale affichait elle aussi des intentions similaires, mais par sa volonté de terminer une réaction, paradoxalement, elle contribua à en créer une autre. Espérant faciliter la réconciliation et mettre fin aux interminables litiges contre les anciens terroristes, la Convention, le 4 brumaire, adopta un décret d'amnistie rendant nul tout mandat d'arrêt appliqué ou non, exécuté ou non, toute mise en accusation, toute procédure et tout jugement portant sur des faits purement relatifs à la Révolution; le décret prévoyait en outre que les individus détenus pour de tels faits seraient simplement relâchés, à la condition qu'ils n'aient pas été impliqués dans la " conspiration du 13 vendémiaire ». Le jour précédent, la loi du 3 brumaire, qui excluait les émigrés et leurs familles de toute charge publique, permit d'évincer tous ceux qui avaient été élus aux assemblées primaires et électorales de fructidor et vendémiaire. C'est armé de cette législation et chargé « d'employer les mesures les plus efficaces pour faire cesser les troubles qui se sont manifestés dans ces départements, poursuivre, faire arrêter et punir les principaux auteurs des complots, les contre-révolutionnaires, les royalistes, soutenir les vrais patriotes, ranimer le patriotisme, et faire respecter les lois " que Stanislas Fréron, ancien Jacobin, conventionnel et terroriste, fut envoyé comme représentant en mission pour la seconde fois dans les départements des Bouches-du-Rhône, Vaucluse, Gard, Hautes-Alpes et Basses-Alpes ${ }^{73}$.

La réaction jacobine

Envoyés tout spécialement pour mettre fin à une réaction, Fréron et ceux qu'il nomma aux charges publiques en créèrent une autre. Moins d'un mois après son arrivée, Fréron avait destitué la municipalité et le district de Marseille, ainsi que l'administration départementale d'Aix, invoquant la loi du 3 brumaire et les accusant de n'avoir pas poursuivi les auteurs des violences partisanes ${ }^{74}$. Quelques mois plus tard, le département à son tour destitua sur des pétitions douteuses de nombreuses municipalités et nomma à leur place d'anciens Jacobins. Fréron inaugura en outre un programme jacobin consistant à poursuivre les prêtres réfractaires, les anciens émigrés et les égorgeurs responsables des meurtres de l'an III; il fit libérer les anciens terroristes qui ne perdirent pas un instant pour exercer leur vengeance sur leurs adversaires personnels et politiques de l'an III et d'avant. Des bagarres, insultes, assassinats et émeutes perpétrés par des "amnistiés" se multiplièrent dans le département, répandant la crainte que la Terreur soit à nouveau à l'ordre du jour ${ }^{75}$. Quelques semaines après l'arrivée de Fréron, des commentateurs locaux et nationaux dénonçaient la "réaction terroriste ", la "réaction fréronienne" qu'il organisait ${ }^{76}$. Comme le remarquait un observateur, «la réaction la plus funeste s'est opérée dans toutes les communes $»^{77}$. Les partisans de Fréron, en revanche, pour la plupart anciens terroristes et membres des sociétés populaires, prétendaient que sa mission avait été salutaire pour les patriotes assiégés et avait mis un terme à la « royale et sanglante 
réaction ». Le concept de réaction politique, à droite comme à gauche, faisait désormais partie du vocabulaire politique de la Révolution en l'an IV.

Le Directoire entérina la politique de Fréron, même si d'aucuns avançaient qu'elle constituait une violation de la Constitution de l'an III et des élections de l'automne précédent $^{78}$. Une fois de plus, le retour de nombreux anciens terroristes au pouvoir modifia le climat politique de la région. Comme on pouvait s'y attendre, la violence des partis persévéra. L'ordre public ne pouvait être maintenu - quand c'était possible - que par une utilisation de plus en plus fréquente des troupes de ligne, qui servaient de rempart entre les factions en conflit ${ }^{79}$. La demande de troupes, en fait, devint un thème récurrent de la correspondance officielle de l'époque, témoignant de la faiblesse des administrations locales et de leur difficulté à maintenir elles-mêmes l'ordre public. Comme ce fut si souvent le cas ailleurs dans la France de l'époque, les autorités civiles invoquaient la nécessité de troupes régulières, et souvent d'une force neutre et imposante, comme unique moyen de maintenir l'ordre dans leurs communautés déchirées par les factions, même si, comme le révélera l'histoire du régime, ces troupes, toujours manquantes et très politisées, étaient rarement imposantes et presque jamais neutres ${ }^{80}$. Cette crise de l'autorité fut en grande partie exacerbée par l'inefficacité des gardes nationaux locaux comme force de l'ordre; bien souvent les compagnies de gardes nationaux étaient elles-mêmes les instruments des factions, généralement une source de désordre bien plus que d'ordre ${ }^{81}$.

L'incapacité persistante des autorités locales, même les mieux intentionnées, à imposer l'ordre et à faire cesser les luttes de faction tenait autant à la faiblesse des moyens qu'elles possédaient pour faire appliquer la loi qu'à leur indifférence à le faire. Évoquant, en germinal an VI, l'arrondissement de Tarascon, le ministre de la Justice rapportait au ministre de la Guerre que « l'action de la justice y est impuissante contre les coupables parce qu'il n'y a pas de forces suffisantes pour assurer l'exécution de la loi $\$^{82}$. On n'insistera jamais assez sur le fait que le personnel judiciaire, que ce soient les juges de paix, directeurs des jurys, jurés ou personnel des tribunaux criminels, était le plus souvent constitué des acteurs du drame des réactions locales: la décision de poursuivre ou non ceux qui s'étaient rendus coupables de violence contre leurs adversaires politiques demeurait de la compétence souveraine de l'autorité judiciaire. La réaction de l'an IV, comme les réactions précédentes et suivantes, fut perpétrée et entièrement dominée par les autorités administratives, militaires et judiciaires.

Alors que Fréron se vantait d'avoir terminé la « réaction fatale » sans faire couler une goutte de sang pendant les cinq mois de sa mission dans la région, la liste des meurtres commis au sein des deux factions contredit ses affirmations. Le récit par Fréron de sa mission, Mémoire historique sur la Réaction royale, écrit principalement pour justifier sa conduite dans le Midi et dénoncer les crimes de la réaction - crimes qui, selon l'auteur, avaient été tolérés par les autorités locales et les représentants en mission à l'époque thermidorienne - suscita un intérêt certain, mais aussi des controverses et une vague de réponses indignées de la part de ceux que Fréron accusait dans son Mémoire ${ }^{83}$. Quelle qu'ait été la légitimité des accusations de Fréron, son emploi du terme "réaction royale " pour caractériser l'histoire politique du Midi en l'an III, notamment dans les Bouches-du-Rhône, forgea la postérité du mot, faisant des termes "réaction» et « royale » un couple célèbre du discours jacobin.

Face à la force croissante du mouvement populaire à Paris et en province, la crainte d'un renouveau terroriste, la persistance de la violence factieuse dans les 
départements, dont les terroristes étaient tenus pour les premiers responsables, la découverte et la répression de la conspiration de Babeuf, ainsi que les élections municipales de thermidor an IV à Aix et Marseille qui eurent lieu dans un contexte de violence extrême, le Directoire modifia sa ligne politique. De nombreux terroristes furent arrêtés et démis de leurs fonctions. Épicentre de ce qu'on appelait à l'époque l'activité anarchiste et foyer de troubles, le Midi provençal nécessitait un homme d'ordre capable d'interposer son autorité entre les deux factions en guerre, afin de donner à la région une certaine stabilité. La politique de réaction était devenue un trait distinctif des Bouches-du-Rhône.

La réaction Willot

53 Pour un gouvernement qui professait sa volonté de rétablir l'ordre et la tranquillité dans un Midi perpétuellement troublé, le choix d'Amédée Willot au poste de général de la 8 e division militaire, qui comprenait l'essentiel de la Provence, n'avait rien de fortuit. Sa mission en l'an $\mathrm{V}$, de fructidor an IV à prairial an $\mathrm{V}$, favorisa un retournement de situation, produisant une nouvelle réaction, cette fois contre les anciens Jacobins. Dans le langage des contemporains, la « réaction fréronienne» fut suivie de la « réaction Willot ».

Noble, militaire de carrière dont la famille avait été persécutée sous la Terreur et qui fut lui-même emprisonné plusieurs mois en 1793 et 1794, suspecté de sympathies royalistes, ami des personnalités antijacobines comme Cadroy et Rovère, Willot ne fit aucun effort à son arrivée dans la région pour cacher ses convictions antiterroristes dans ses actions comme dans sa correspondance avec le Directoire ${ }^{84}$. En effet, si ses premières proclamations appelaient à la neutralité, ses sympathies allaient clairement à une faction plus qu'à une autre, la faction qui partageait sa haine envers les anciens Jacobins et leurs partisans ${ }^{85}$. S'il n'avait pas les pouvoirs, en tant que commandant militaire, de destituer les administrateurs, il pressait néanmoins le gouvernement central à écarter des postes publics ceux qu'il décrivait comme " anarchistes ».

La conduite de Willot lui valut l'hostilité des anciens Jacobins comme l'éloge de leurs opposants. Certaines municipalités, celle de Marseille en particulier, ainsi que de simples citoyens, accusèrent Willot d'autoriser des arrestations arbitraires, de persécuter les républicains, d'imposer un despotisme militaire et même de préparer la contre-révolution en protégeant les prêtres réfractaires, les émigrés et les égorgeurs ${ }^{86}$. Willot servait de symbole aux allégeances partisanes: ceux qui avaient fait l'éloge de Fréron dénigraient maintenant Willot. Ses critiques lui décernèrent les sobriquets de " roi de Marseille », de «tyran Willot » et de « despote du Midi ${ }^{87}$.

La politique partisane de Willot, loin de calmer la lutte des partis, contribua à l'exacerber dans la région. Son séjour controversé illustre bien la nature problématique des forces militaires à l'époque : la tentation des militaires - les officiers comme les troupes de ligne - de prendre parti dans les conflits locaux. Beaucoup d'autres protagonistes du conflit, qui participaient aux émeutes d'Arles ou de Marseille, ou à des actes de violence plus limités, étaient marqués par leur passé révolutionnaire et mêlés à des luttes ou règlements de compte qui dataient des premières années de la Révolution. "Le désir de vengeance, commentait le journaliste Beaugeard, est dans le cœur de ceux que les oscillations et les réactions ont tantôt élevés et tantôt abattus. " ${ }^{88}$

57 Parmi les victimes des violences perpétrées lors du séjour de Willot se trouvaient, bien sûr, un grand nombre d'anciennes victimes des violences antijacobines de l'an III ${ }^{89}$. Les actes de violence allaient des destructions de propriétés aux meurtres sur les deux 
sexes, en passant par les cambriolages et les coups, et entraînèrent la fuite de centaines de personnes. La violence perdura parce que ceux qui interprétaient et exécutaient les lois appartenaient eux-mêmes à la faction opposée. Les juges de paix élus, les directeurs du jury, le personnel des tribunaux criminels et les administrateurs poursuivaient les membres d'une faction et pas ceux de l'autre. Un observateur parisien envoyé dans la région en l'an V notait que "les organes de la justice, comprimés par la crainte, lorsqu'il s'agit d'affaires criminelles et de parti, n'osent faire usage de tous les moyens que la loi leur indique pour découvrir la vérité $»^{90}$. Le manque d'hommes neutres au sein des autorités judiciaires et administratives, de la garde nationale et des troupes de ligne, toujours en nombre insuffisant, condamnait le département des Bouches-duRhône, comme bien d'autres, à de perpétuelles luttes de factions.

Les récits de cette violence constituent un thème dominant des documents administratifs et judiciaires de l'époque, et ils étaient très largement rapportés dans la presse locale et nationale, particulièrement à l'approche des élections de l'an V. Comme le Journal des hommes libres, de tendance néo-jacobine, l'écrivait en ventôse V: «Depuis l'arrivée de Willot, tous les crimes sont à l'ordre du jour dans nos contrées ${ }^{91}$. Localement, l'ancien clubiste et terroriste Peyre-Ferry fils, éditeur de l'observateur $d u$ Midi, se lamentait de la violence continuelle contre les anciens terroristes: "L'arbitraire le plus tyrannique continue à peser sur eux, et les meurtres partiels [...] se répètent chaque jour dans le midi $»^{92}$. En Arles, la longue lutte entre les deux factions engendra de nouvelles insurrections populaires en décembre 1795 et en 1797, insurrections qui révèlent d'une manière frappante la continuité du conflit ${ }^{93}$. Le 4 nivôse an IV et les jours suivants, la confrontation entre les partis prit la forme d'affrontements entre foules armées, incluant femmes et enfants, de patrouilles illégales composées en partie d'anciens terroristes, dont beaucoup avaient été récemment amnistiés, qui perpétrèrent des arrestations arbitraires, des pillages ainsi que le meurtre de trois personnes, deux monnaidiers et un chiffoniste. Comme souvent, chaque parti rejeta la responsabilité de ces violences sur l'autre parti. De même en 1797, le 25 nivôse $V$, nombre de ces personnes, hommes comme femmes, participèrent à des rassemblements armés après l'arrestation et le meurtre d'un ancien terroriste, incident qui provoqua la mobilisation du parti monnaidier aux cris de "puisqu'il n'y a point d'amnistie pour les patriotes, il faut nous venger à coups de couteaux $»^{94}$. Si aucun membre des deux partis ne fut tué lors de ces troubles, et ce malgré les appels à la violence, cet incident reflète comme bien d'autres troubles, la persistance des rivalités entre factions.

Les élections de l'an $\mathrm{V}$ dans le département furent précédées par un accès d'agitation et de violence entre les partis, qui nécessita la fréquente mobilisation de troupes, souvent en vain, afin de maintenir un semblant d'ordre. Plusieurs villes, notamment Gardanne, Trets, Saint-Chamas, Graveson, Eguilles et Noves, furent mises en état de siège sous contrôle militaire, s'ajoutant à la longue liste qui comprenait déjà Marseille, Aix, Aubagne, Martigues, Tarascon, Château-Renard et Arles. Les élections enregistrèrent des records de participation pour toute la période directoriale dans les Bouches-duRhône; à Marseille, les élections mobilisèrent $40 \%$ des votants pour les trente-trois sections de la ville ${ }^{95}$. Les nouveaux officiers municipaux des principales villes avaient souvent détenu des charges publiques sous l'Ancien Régime, pendant la révolte fédéraliste ou la réaction de l'an III, ou avaient été élus en vendémiaire ou brumaire an IV, quand ils n'étaient pas des nouveaux venus en politique. En Arles par exemple, cinq des neuf officiers municipaux de l'an V appartenaient à la municipalité de 1789 ; à 
Aubagne, six des huit officiers municipaux étaient nouveaux, et tous conservateurs ; à Salon, deux venaient de l'Ancien Régime, un avait été fédéraliste et un autre nommé par Cadroy; à Aix, parmi les neuf officiers municipaux, un venait de l'Ancien Régime, un de la période thermidorienne et six avaient été élus au début de l'an IV. Ces élections représentaient donc clairement la victoire d'un parti contre un autre, la victoire de la réaction, selon les opposants. En effet, en Arles, sept des neuf officiers municipaux appartenaient au parti chiffoniste, qui s'opposait aux monnaidiers depuis 1789. Willot lui-même fut élu triomphalement comme député au Conseil des Cinq-Cents pour les Bouches-du-Rhône, aux côtés du chiffoniste antijacobin Jean-François Blain, d'Arles.

60 Mais le mandat de Willot, comme celui de son collègue Cadroy, fut de courte durée. Il figura en effet parmi les 53 députés condamnés à la déportation lors du coup d'État du 18 Fructidor et fut déporté en Guyane. Le coup d'État du 18 Fructidor fut perçu par les Jacobins de la région, qui avaient été exclus du pouvoir par les élections de l'an $\mathrm{V}$, comme la fin de l'oppression et la défaite de la contre-révolution. Le coup d'État avait mis un terme à la réaction royale.

La contre-réaction

61 Le coup d'État de Fructidor fut suivi d'une purge du personnel administratif et judiciaire des départements des Bouches-du-Rhône, du Var et du Vaucluse. Pour les anciens Jacobins, les terroristes et tous ceux qui avaient dû s'enfuir ou se cacher pendant les persécutions «royalistes» de l'an III et V, la journée de fructidor marqua un tournant et fut rapidement décrite, avec force lyrisme, comme la journée qui sauva la République assiégée des mains de royalistes invétérés ${ }^{96}$. Pour un grand nombre d'émigrés non rayés des listes, pour le personnel administratif et judiciaire élu en germinal an $\mathrm{V}$ et pour un nombre significatif de modérés et d'antijacobins, cet événement inaugura une nouvelle réaction. Il raviva les craintes d'une nouvelle Terreur.

Des centaines de personnes dans le département et dans la France tout entière furent obligées de fuir le pays ou de se cacher, souvent pour la deuxième fois. Dans le département et la région, ceux qui étaient suspectés d'avoir pris part à une des réactions royalistes de l'an III ou V étaient systématiquement dénoncés, arrêtés ou assassinés ${ }^{97}$. La création de commissions militaires à Marseille, Avignon, Toulon, Tarascon et Nice confirma les peurs d'une nouvelle Terreur en préparation : quelques semaines après la réception de la loi du 19 fructidor, les administrations purgées du département des Bouches-du-Rhône commencèrent à arrêter ceux qui ressortissaient de cette loi, ce qui entraîna des centaines d'arrestations - non seulement des émigrés et des prêtres réfractaires, mais aussi d'anciens fédéralistes et tous ceux soupçonnés d'être des sabreurs. Certains individus avaient été condamnés comme égorgeurs dans les prisons d'Aix, assassins en l'an III et V ou membres de la bande d'Aubagne, et certains d'entre eux montèrent jusqu'à l'échafaud en criant "vive Willot, vive Cadroy! » et en chantant le Réveil du peuple ${ }^{98}$.

63 Les anciennes autorités judiciaires, ainsi que les administrateurs, se virent accusés d'avoir perpétré ou du moins toléré la «réaction» contre les "patriotes» et les " républicains » jusqu’à leur purge, à la suite de la " journée heureuse du 18 fructidor ». Comme le fit remarquer le commissaire du Directoire exécutif auprès du département des Bouches-du-Rhône: "Tant que la Réaction royale a pesé sur nos contrées, ces brigands soutenus par des autorités criminelles qui légitimaient ces horreurs se sont 
cru eux-mêmes une autorité privilégiée " $^{99}$. À Marseille, Barry aîné, le commissaire du Directoire exécutif auprès de la municipalité du Nord, ainsi que ses collègues auprès de la municipalité du Midi, et le tribunal de police correctionnelle, furent tous diversement accusés et destitués pour avoir abusé de leur position en lançant des mesures d'oppression contre les "patriotes", en servant de conseiller intime au « traître de Willot » et même en organisant les compagnies de Jésus et du Soleil ${ }^{100}$. Avec la nomination d'un nouveau personnel judiciaire, allant des présidents du tribunal criminel aux juges de paix des diverses villes des Bouches-du-Rhône, anciens Jacobins pour la plupart, des procédures judiciaires furent menées à l'encontre d'un bon nombre de ceux considérés comme responsables des crimes commis lors des précédentes réactions, en particulier lors des massacres des prisons perpétrés l'été de l'an III à Aix, Marseille et Tarascon, sans oublier les crimes attribués aux divers membres de la notoire « bande d'Aubagne $»^{101}$.

Et c'est pendant cette période que des centaines de victimes des « dernières » réactions - ceux qui se disaient victimes des "réactions Cadroy " ou "réaction Willot» ainsi qu'on les appela - demandèrent des indemnités pour les différents supplices endurés ${ }^{102}$. Sur le plan national et local, ces réactions étaient dorénavant invariablement qualifiées de «royalistes $»^{103}$. Le département des Bouches-du-Rhône, ainsi que l'affirma sans équivoque l'administration centrale, fut « le théatre le plus ensanglanté de la réaction royale »104. Tandis que d'autres départements, comme le Vaucluse, le Rhône, le Gard et la Loire, avaient eux aussi assisté à de féroces et fatales attaques sur d'anciens Jacobins, les Bouches-du-Rhône acquirent la réputation, largement méritée, de département où le massacre des "patriotes" compta parmi les plus prolongés et prémédités. Les officiers locaux, notamment judiciaires, furent tenus responsables de ces actes, coupables de ce que l'on décrivait comme une blâmable inertie, une partialité et une complicité entraînant l'impunité criminelle de ceux qui avaient été impliqués dans les crimes des diverses réactions ${ }^{105}$. De fait, les actes de plusieurs officiers locaux, tels les directeurs du jury de Tarascon ou de Marseille, en libérant la plupart de ceux qui avaient été accusés d'avoir participé aux massacres des prisons de ces villes, semblent alimenter les assertions de méfaits judiciaires.

Mais la victoire écrasante des anciens clubistes, dont un nombre non négligeable d'anciens terroristes, aux élections communales et départementales de l'an VI corrobora les craintes d'une autre réaction, menaçant à son tour l'ordre public. En effet, en Arles, sept des neuf officiers municipaux appartenaient à la faction des monnaidiers, dont un avait été nommé par Maignet en 1794 et quatre par Fréron en 1796 ; à Aix, quatre des officiers municipaux élus en l'an VI avaient été fonctionnaires sous la Terreur et avaient tous été membres de la société des Antipolitiques; à Salon, Marseille et Aubagne, comme dans d'autres communes, des modèles similaires ont pu être observés. Il n'est guère surprenant qu'après les nombreuses scissions formées dans les Bouches-du-Rhône et ailleurs au cours des élections de l'an VI, suivies par l'annulation partielle des résultats électoraux, le Directoire exécutif, à l'approche des élections de l'an VII, conseilla aux électeurs d'éviter l'une ou l'autre forme de réaction, également dangereuse : «Écartez au contraire des fonctions importantes d'électeur et de toutes autres fonctions publiques tous ceux qui ont figuré dans la réaction royale et dans l'atroce régime révolutionnaire ${ }^{106}$. Quelle que fût la nature de la réaction, le phénomène fut perçu comme destructeur, voire fatal à la République. Et dans les Bouches-du-Rhône, malgré le succès continu des anciens Jacobins et de leurs alliés aux élections de l'an VII, l'inquiétante augmentation du brigandage semblait présager une 
réaction opposée, une nouvelle réaction royale visant la destruction totale de tous les républicains ${ }^{107}$. La stabilité politique ne fut jamais garantie dans la plupart des communes des Bouches-du-Rhône pendant la décennie révolutionnaire - une réalité que beaucoup imputèrent aux incessantes réactions du Midi ${ }^{108}$.

Quelle que soit leur tendance politique, Jacobins ou antijacobins, civils ou militaires, les autorités constituées et les commentateurs, écrivant à la suite de tant de réactions, craignaient qu'elles ne fussent une source de désordre, de lutte de factions, une période où une Terreur en remplaçait une autre. Tout changement soudain dans la vie politique nationale portait la promesse ou la menace d'une nouvelle réaction. Il n'est donc pas étonnant que la nouvelle du coup d'État du 18 Brumaire ait été reçue dans la région avec appréhension, comme susceptible de provoquer une nouvelle réaction, royaliste ou terroriste, selon les espoirs et les craintes des commentateurs. Il fallut des mois aux autorités locales pour comprendre la portée réelle du coup de Bonaparte. Mais la dernière réaction de la Révolution avait eu lieu.

Les réactions du Midi - ou systèmes de réactions comme elles furent parfois appelées rythmèrent la vie politique de la Révolution dans le Midi provençal. Les contemporains, à l'échelle locale et nationale, commentaient fréquemment la continuité et la quasi omniprésence de la violence engendrée par les luttes de factions dans la région. Depuis le début de la décennie révolutionnaire, les conflits politiques se caractérisèrent, à divers degrés d'intensité, par une lutte des deux partis ou des factions dans les communes, grandes, moyennes et petites. Ce conflit se centra largement sur la lutte de pouvoir entre les Jacobins et leurs adversaires pour le contrôle de la vie politique municipale et le pouvoir politique. Il prit une dimension socio-économique, les Jacobins et leurs opposants appartenant généralement à des milieux distincts : les membres des sociétés populaires des grandes communes étaient issus du monde des artisans et des petits commerçants, même s'il existait entre eux, comme parmi les fédéralistes, des différences sociales au sein de chaque groupe, composé de simples membres et d'une élite. En accord avec la structure professionnelle et la géographie sociale de la vie urbaine, chaque groupe avait mainmise sur certains quartiers, fréquentait certains cafés, et les membres se reconnaissaient par un code vestimentaire particulier, ainsi que par des chansons et symboles. La question débattue de l'appartenance de classe n'est donc pas absente des conflits politiques du Midi. Le caractère très localisé des luttes de partis souligne l'importance d'une analyse économique, sociale et politique des factions, afin de mieux comprendre la vie politique sous la Révolution. Même s'il fut influencé par des événements nationaux et emprunta un langage national, le conflit demeura fondamentalement local dans les luttes de pouvoir intercommunales.

L'utilisation d'un langage politisé et polarisé opposant royalistes et républicains, révolutionnaires et contre-révolutionnaires, crée une vision inadéquate du conflit entre les partis. Le label politique faisait partie intégrante de la stratégie de conflit, et l'application de ces termes, de même qu' "aristocrate", "buveur de sang» ou " honnêtes gens ", doit être interprétée à la lumière des loyautés et du langage de parti. Cela ne tend pas à nier l'existence - réelle ou perçue - du royalisme et de la contrerévolution en Provence et ailleurs à cette époque. Néanmoins, ces dénominations ne doivent pas être comprises comme un reflet fidèle des engagements idéologiques. Les Jacobins, en particulier, traitaient leurs opposants de contre-révolutionnaires, quand bien même beaucoup, notamment la majorité des fédéralistes, étaient des républicains convaincus. De même, les antijacobins stigmatisaient fréquemment les clubistes comme 
des « anarchistes ». Le langage politique de l'époque reflétait et façonnait l'extrémisme factionnel.

Le terme " réaction » fit son entrée dans le vocabulaire politique de la Révolution après thermidor an II. À l'issue du coup d'État de fructidor an V, de nombreuses autorités constituées, souvent composées d'anciens Jacobins, utilisèrent le terme pour décrire la longue période de persécution que les "patriotes » ou "républicains » avaient subie pendant deux ans. Cette réaction ininterrompue était invariablement qualifiée de royaliste. Or ce qui fit la particularité du Midi provençal, et des Bouches-du-Rhône en particulier, fut sans nul doute l'alternance des réactions dirigées contre les anciens clubistes et leurs partisans ou contre leurs adversaires. Ces réactions furent le produit de personnalités et de mesures d'envergure nationale, autant que de facteurs locaux.

La persistance des réactions, il faut bien le souligner, dramatisa l'incapacité - ou, parfois, la réticence - des autorités civiles, judiciaires et militaires à régler le problème fondamental de l'ordre public pendant cette période. Le manque chronique de troupes de ligne priva les autorités des moyens d'appliquer la loi. En effet, tout au long de la décennie révolutionnaire, et plus particulièrement sous la Convention thermidorienne et le Directoire, les autorités constituées des Bouches-du-Rhône, et d'autres départements en France, ne cachèrent pas leur incapacité à protéger les personnes et les propriétés sans l'aide de la force militaire, ce qui témoigne de l'inefficacité de la police locale, des gardes nationaux et des gardes champêtres en matière d'ordre public. Les autorités civiles et judiciaires considéraient l'armée comme un espoir - aussi fervent que vain - d'obtenir une force neutre qui agirait sans partialité pour empêcher les divers partis de se livrer à des vengeances particulières. "Le seul moyen de le garantir des efforts des deux factions qui tentent de le déchirer et de le détacher de la République, remarquait un observateur, est d'y faire passer une force armée capable de comprimer tous les agitateurs et tous les brigands qui l'infestent $»^{109}$. La requête d'une force imposante, étrangère aux partis locaux, constitua donc un thème récurrent de la correspondance des autorités pendant la décennie révolutionnaire, notamment dans le Midi.

71 L'instrumentalisation des institutions politiques et des postes publics pour la promotion des intérêts des factions caractérisa également la période, notamment dans cette région particulièrement conflictuelle. La politisation du pouvoir judiciaire - des juges de paix, des directeurs de jury, des jurés eux-mêmes et des membres des tribunaux - sa négligence, voire sa complicité, ainsi que la timidité des témoins, générèrent une véritable paralysie dans la poursuite des crimes engendrés par les différentes réactions. L'impunité enhardit le crime autant qu'elle favorisa l'injustice et entretint le désir de vengeance populaire. Comme l'observa le commissaire du gouvernement près du tribunal de première instance séant à Marseille à l'adresse du ministre de la Justice en décembre 1800 : «Presque tous les crimes de tous les partis et de toutes les factions sont restés impunis, l'action de la justice n'a presque jamais été dirigée par l'impartialité [...] $\gg^{110}$. Si cette observation semble quelque peu exagérée, il n'en reste pas moins avéré que les accusations d'impunité, souvent issues de la justice partisane, persistèrent tout au long de la décennie, contribuant à un climat politique particulièrement enclin aux réactions.

Dans son essai sur les réactions, Benjamin Constant insiste avec justesse sur le fait qu'une réaction mène souvent à une autre ${ }^{111}$. En effet, ce qu'on pourrait décrire comme la politique de la vengeance façonna toute une facette de l'histoire de la Révolution 
dans la région. Beaucoup de caractéristiques de la politique des factions du Sud-Est se retrouvent aussi ailleurs en France : à savoir l'inefficacité et la politisation des gardes nationaux et de la police, l'incapacité des autorités constituées à faire face au problème de l'ordre public sans recours au militaire, la partialité des tribunaux, des fonctionnaires publics et des militaires dans l'exercice de leurs fonctions, la violence verbale et physique entre des partis en apparence irréconciliables, l'usage systématique mais stratégique de dénominations politiques pour stigmatiser l'adversaire, l'héritage de la Terreur et la peur de son retour, ainsi que la peur du royalisme et de la contrerévolution comme moteurs de l'action politique.

Le Midi se posa comme l'une des régions les plus troublées de la France révolutionnaire, marqué par un conflit politique d'une rare durée et intensité. Chaque phase de la Révolution - ainsi que les douloureux clivages créés par la révolte fédéraliste et la période de la Terreur - intensifia l'héritage de la haine. Toutes les autorités s'accordaient à dire que la persistance des réactions posait un défi à l'ordre public et à la possibilité d'en finir avec la Révolution. «Si donc nous voulons terminer la Révolution, il faut mettre un terme aux réactions politiques, qui ne sont autre chose que des convulsions réitérées qui affaiblissent toujours davantage le corps de l'État et le conduiraient à une mort certaine, si le médecin ne tempérait les accès du mal par le traitement qu'il ordonne au malade et par le régime doux qu'il lui prescrit dans sa convalescence ", écrivait Laporte, alors membre du Comité de Salut public, à Cadroy, ce qui ne manque pas d'ironie compte tenu de la suite des événements ${ }^{112}$. Et beaucoup d'autres se firent l'écho de cette croyance répandue selon laquelle les réactions entraîneraient un jour ou l'autre la chute de la République. Les réactions furent à la fois ennemies de la loi et complices de l'instabilité politique. Et ces mêmes réactions constituèrent l'essence du processus révolutionnaire dans le département des Bouchesdu-Rhône, comme dans beaucoup d'autres régions de France.

\section{NOTES}

1.Cet article est une version développée de notre communication au colloque de French Historical Studies tenu à Paris en juin 2004.

2.Gazette Nationale $\mathrm{n}^{\circ}$ 54, 24 brumaire an IV, p. 215.

3.Sur le sujet de la violence dans le Midi, voir entre autres : Stephen CLAY, « Le Massacre du fort Saint-Jean, un épisode de la Terreur blanche à Marseille » dans Michel VovelLE (dir.), Le Tournant de l'an III : réaction et terreur blanche dans la France révolutionnaire, Paris, Éditions du CTHS, 1997, p. 579 - 583 ; Richard C. СовB, Police and the People : French Popular Protest, 1789-1820, Oxford, Oxford University Press, 1970, p. 131-150 ; Colin LuCAS, "Themes in Southern Violence after 9 thermidor ", dans Gwynne LewIS et Colin LuCAS (dir.), Beyond the Terror : Essays in French Regional and Social History, 1794-1815, Cambridge, Cambridge University Press, 1983, p. 152-194 [. [.0;0; Michel Vovelle, « Massacreurs et massacres : aspects sociaux de la contre-révolution en Provence, après Thermidor ", dans Les Résistances à la Révolution, Paris, Imago, 1987, p. 141-150 ; Warren WiLSON, « Les 
journées populaires et la violence collective dans le Vaucluse rural après Thermidor ", Canadian Journal of History, 28 (avril 1993), p. 41-57.

4.Le phénomène des différentes réactions dans le Midi a été déjà analysé plus brièvement dans notre article, «Réaction dans le Midi : le vocable de la vengeance ", dans Jacques GUILHAUMOU et Raymonde MoNNIER (dir.), Dictionnaire des usages sociopolitiques (1770-1815), t. 6, Paris, Klincksieck, 1999, p. 157-186.

5.Stanislas FRÉRON, Mémoire historique sur la Réaction royale et sur les massacres du Midi, Paris, Baudoin Frères, 1824 ; Benjamin ConstANT, Des Réactions politiques, Paris, ChampsFlammarion, 1988 ; François-Auguste MIGNET, Histoire de la Révolution française depuis 1789 jusqu'en 1814 (2 vols), Paris, Didier et cie, 1875 ; Jean-Joseph François Poujoulat, Histoire de la Révolution Française (2 vols), Tours, Mame, 1848 ; Edgar QUINET, La Révolution, Bruxelles, A. Lacroix et Verboeckhoven, 1865 ; Louis-François TissoT, Histoire complète de la Révolution française, 6 vols, Paris, Silvestre, 1834-1835 ; Albert MATHIEZ, La Réaction thermidorienne, Paris, Armand Colin, 1929.

6.Pour une sélection représentative de ce thème dans des correspondances privées, des lettres officielles et des adresses, voir Archives Nationales (AN) DIII 30 (Lambesc); AN DIII (Marseille) 30 ; AN F7 7138 ; F7 7338 ; F7 7394 ; Archives Départementales des Bouches-du-Rhône (AD Bouches-du-Rhône) L 85 ; L 蔔 249 ; Archives municipales (AM) Aix LL 82 ; AM Marseille, 4D29. De plus, cette notion était au cœur de ce qu'on pourrait appeler la presse néo-jacobine, localement comme nationalement, et développée dans de nombreux numéros de La Sentinelle, Journal des Hommes libres, L'Ami des Lois et dans L'Observateur du Midi et le Journal de Marseille. Pour une étude des thèmes du royalisme et d'autres dans la presse locale, Stephen CLAY, « La guerre des plumes : la presse provinciale et la politique de faction sous le Premier Directoire à Marseille, 1796-1797 », Annales historiques de la Révolution française, 308 (1997), p. 221-248.

7.Sur les réseaux d'agents britanniques actifs en Provence à l'époque révolutionnaire, voir Warren WiLson, « Les réseaux contre-révolutionnaires en Provence sous la Révolution française », thèse de 3e cycle, Université d'Aix-en-Provence, 1985. 8.Journal de Marseille (JM). $\mathrm{N}^{\circ}$ 5, 16 brumaire IV, p. 405.

9.Voir, en plus des travaux cités en note 3, Bruno BENOIT : « Chasser le mathevon à Lyon en l'an III ", Le Tournant de l'an III. Réaction et terreur blanche dans la France révolutionnaire, Paris, Éditions du CTHS, 1997, p. 497-507 ; Charles JoLIVET, La Révolution dans l'Ardèche, Largentière, 㷂 E. Mazel, 1930 ; Colin LuCAS, « The Problem of the Midi in the French Revolution ", Transactions of the Royal Historical Society 28 (1978), p. 1-25 ; René MoULINAS, «Le département du Vaucluse en 1795 媐: la Contre-révolution en marche? », Le Tournant de l'an III, ibid, p. 529-538.

10.Voir en particulier, les différents « Tableaux des Assassinats » rédigés par plusieurs villes dans le département, dans AN BB13 183.

11.Voir Colin LUCAS, "The Rules of the Game in Local Politics under the Directory ", French Historical Studies, 16-2(1989), p. 345-71.

12.Voir en particulier la série d'excellents articles et le livre de Monique CuBELLs, par exemple : «Les mouvements populaires du printemps 1789 en Provence », Provence Historique, 1986, p. 309-323 ; idem, « Marseille au printemps de 1789 : une ville en dissidence », Annales du Midi (1986), p. 67-91; ibid, « Aix-en-Provence en 1789. Le Mouvement et la Résistance ", Dix-huitième siècle, 20 (1988), p. 161-177 ; ibid., Les horizons de la liberté : naissance de la Révolution en Provence (1787-1789), Aix-en-Provence, Edisud, 1987. 
13.Pour une étude des conflits politiques en Arles pendant les premières années de la Révolution, voir Fabio SAMPOLI, Politics and Society in Revolutionary Arles: Chiffonistes and Monnaidiers, (P.h.D dissertation) Yale Univ., 1982 ; Pierre SERNA, Antonelle - aristocrate révolutionnaire, 1747-1817, Paris, Éditions du Félin, 1997. Les statistiques présentées ici sont tirées de notre propre analyse à partir des AM d'Arles 1D1-8.

14. Ces conclusions sont fondées sur notre étude de la politique municipale et $\mathrm{du}$ personnel à Aix, Arles, Marseille, Salon et Tarascon, et des études locales par Christiane DEROBERT-RATEL, Institutions et vie municipale à Aix en Provence sous la Révolution, Aix-enProvence, Edisud, 1981 ; SAMPOLI, ibid ; Cyril BELMONTE, « Les luttes politiques à Aubagne sous la Révolution française, 1789-1799 » mémoire de maîtrise, Université d'Aix-enProvence, 1999 ; Cyril BelmonTE, « Aubagne en Révolution. Luttes Sociales et Bipolarisation Politique », Provence historique, 208 (2002), p. 233-247.

15.Jean Boutier, Philippe Boutry, «Les Sociétés populaires », vol. 6, Atlas de la Révolution française, Paris, éditions de l'EHESS, 1992, p. 43, 80, 99-100 ; Michel VovELLE, « Villes, bourgs, villages : le réseau urbain-villageois en Provence », De la Cave au Grenier, Québec, S. Fleury, 1980, p. 19-38; Maurice AGULHON, Pénitents et francs-maçons de l'ancienne Provence, Paris, Fayard, 1968, p. 262-5 ; Henri LABRoue, Le club jacobin de Toulon, 1790-1796, Paris, Editas, 1907 ; Malcolm CROOK, « Les Jacobins de Toulon », dans Michel PERONNET (dir.), Les Jacobins du Midi, Montpellier, 1989, p. 1- 13 ; Félix PoNTEIL, « La Société populaire des antipolitiques ", Revue historique de la Révolution française, 18 (1916) ; Claude TACETTI, «La société populaire des antipolitiques d'Aix » (DES, Univ. Aix, 1969) ; Michael KENNEDY, The Jacobin Club of Marseille, 1790-1794, Ithaca, Cornell University Press, 1973 ; Martine LAPIED, « Les Jacobins avignonnais et comtadins » dans Michel PERRONET (dir.), Les Jacobins du Midi, op. cit., p. 77-88 ; Martine LAPIED, Le Comtat et la Révolution française - naissance des options collectives, Aix-en-Provence, Presses Universitaires de Provence, 1996.

16.Pour une illustration de cette politique, voir entre autres, les délibérations des sociétés populaires du département, notamment celle des Antipolitiques d'Aix (AD Bouches-du-Rhône L2026-2032), celle de Marseille (L 2071-2), celle de Salon (L 2078) ; diverses sociétés : L 2064 ; L 1319 ; L 2079 ainsi que les imprimés portant sur le club jacobin de Marseille déposés à la Bibliothèque municipale de Marseille.

17.Toute la période des élections, avant, pendant et après, redoutée par les autorités constituées militaires et judiciaires comme une période de fermentation et confrontation des partis, a souvent nécessité la mobilisation des troupes pour le maintien de l'ordre. Voir en particulier pour le département des Bouches-du-Rhône, AN F1cIII BDR 1, 10 ; F7 4268 ; BB18 179. AD Bouches-du-Rhône L 122 ; L 136 ; L 140 ; L 1507. 18.Cette référence et d'autres statistiques portant sur le profil socio-économique du personnel administratif et judiciaire des villes d'Aix, Arles, Marseille, Salon, et Tarascon sont tirées de notre étude du personnel et des élections dans ces villes pendant la décennie révolutionnaire, ainsi que de l'analyse de la composition des sociétés populaires des communes où une telle documentation était disponible, complète ou incomplète. L'étude des niveaux de richesse a été réalisée à partir de la contribution patriotique, des emprunts forcés de l'an II, l'an IV et l'an VII, des contributions foncières et de certains actes notariés.

19.AN F7 3659 (1 et 2) ; AD Bouches-du-Rhône L 51 ; L 122 ; L 292 ; L 1507.

20.AN F7 3659 (2). 
21.AN DXXIX 2 ; DXXIXbis 41 et 42 ; DXXIX 54 à 56 ; F7 3659 (1 et 2). AD Bouches-duRhône L 38, L 51, L 122, L 205, L 528, L 1507.

22. Comme le général Chabert l'expliquait à Merlin de Douai, alors membre du Directoire exécutif, en l'an VI, « la commune de Marseille est celle qui depuis le commencement de la révolution a constamment donné le ton aux autres communes du Midi ».

23.Pour l'histoire de la Société des Amis de la Constitution de Marseille à ses débuts voir, Michael KENNEDY, The Jacobin Club of Marseille, op. cit., et Jacques GUILHAUMOU, Marseille républicaine (1791-1793), Paris, Presses de la FNSP, 1992.

24.Pour l'utilisation des mots « aristocrate » et « contre-révolutionnaire » par le parti patriote au début de l'époque révolutionnaire, voir : AN F7 3659(1) : Relation de ce qui s'est passé dans la Séance de la Société des amis de la Constitution d'Arles, du 9 et 10 juin 1791 ; BM Marseille (FP) 4528*: La Mort de la bête à cent têtes, ou l'enterrement de l'Aristocratie et des Aristocrates, 30 avril 1790 ; BM Marseille 4717 (28) : Adresse aux Parisiens, 3 février 1791.

25. Michel Vovelle, « Les troubles sociaux en Provence de 1750 a 1792 », dans De la Cave au Grenier, op. cit., p. 221-262.

26.AN F7 3659(2) et (3); AD Bouches-du-Rhône L 43 ; L 44 ; L 92 ; L 292 ; L 943 ; L 1932 ; L 1945 ; L 3104 ; BM d'Arles, M 633, Pierre Véran (journal historique de la ville d'Arles) (1792) ; AM Arles, D2 ; D422. Paul Albert ROBERT, Le Tribunal Populaire de Marseille, Paris, A. Rousseau, 1913 ; Michael KENNEDY, The Jacobin Club of Marseille, 1790-1794, op. cit., p.

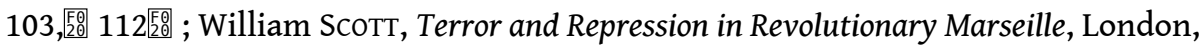
Macmillan, 1973, p. 33, 50, 51 ; Cyril BELMONTE, Les Luttes politiques à Aubagne sous la Révolution française, 1789-1799 (mémoire de maîtrise, Université d'Aix-en-Provence, 1999), p. 24, 28-31.

27.BM d'Arles M628 : Tableau des chiffonières mises sur des ânes et martyrisées par les monnaidiers dans le mois de septembre 1792.

28.Sur la violence populaire à Toulon pendant l'été 1792, voir Malcolm CROOK, Les Journées révolutionnaires à Toulon, Nîmes, éditions Jacqueline Chambon, 1989, p. 41-49 et ibid., Toulon in war and Revolution. From the ancien regime to the Restoration, 1750-1820, Manchester, Manchester University Press, 1991, p. 115-117.

29.Voir en plus de Paul-Albert ROBERT, Le Tribunal populaire de Marseille, op. cit., AD Bouches-du-Rhône L 483, et L 3100 à 3108.

30.AD Bouches-du-Rhône L 1840 ; L 3038 ; L 3069 et surtout les dénonciations devant le tribunal populaire (L 3108)

31.Pour l'affaire de Salon, voir L 3044-3047 ainsi que Jacques GuILHAumou, Marseille Républicaine, op. cit., p. 137-159.

32.AD Bouches-du-Rhône L 288 ; L 3043 ; AM Aix LL90.

33.AM Arles D422.

34.Pour le tribunal populaire voir AD Bouches-du-Rhône L 3104 à 3108 ; et Paul-Albert ROBERT, Le Tribunal populaire de Marseille, Paris, A. Rousseau, 1913 et Monique CuBELLS, «Les Jacobins devant la Justice fédéraliste de Marseille : L'affaire de Salon », dans Les Fédéralismes. Réalités et représentations, 1789-1874, Actes du colloque de Marseille, sept. 1993, Aix-en-Provence, PUP, 1995, p. 117-125.

35. Ce sentiment d'indignation contre les contributions forcées et autres actes arbitraires, contre l'anarchie et l'intrigue incarnées par les sociétés populaires ou des personnages tels que Marat a été diffusé au sein des sections, dans tout le département ; voir parmi d'autres, AD Bouches-du-Rhône L 1933, 1960, 1969, 1987, 2023. 
36. Cette section s'appuie sur Georges GUIBAL, Le Mouvement fédéraliste en Provence en 1793, Genève, Megariotis réédité en 1908 et 1979 ; John CAMERON, The Revolution of the Sections of Marseilles Federalism in the Department of the Bouches-du-Rhône in 1793, (PhD dissertation., University of North Carolina, 1971) ; Jacques GUILHAUMOU, Marseille républicaine (1791-1793), Paris, op. cit., 1992 ; Paul HANson, The Jacobin Republic Under Fire. The Federalist Revolt in the French Revolution, Penn State University Press, 2003 ainsi que d'autres études locales comme celles de BELMONTE, SAMPOLI et RATEL. Mais avant tout, elle est tirée de ma propre lecture approfondie des documents abondants et exceptionnellement riches - registres et liasses - portant sur la révolte fédéraliste dans le département des Bouches-du-Rhône et de ma propre reconstruction du personnel fédéraliste dans les grandes villes du département.

37.AD Bouches-du-Rhône L 1987 : section 7, 1 mai 1793.

38.AD Bouches-du-Rhône L 128.

39.Voir avant tout l'éloquent Manifeste de Marseille aux Républicains Français (12 juin 1793, AD Bouches-du-Rhône L 3120), adresse anti-parisienne, anti-montagnarde, et profondément républicaine.

40.Voir AD Bouches-du-Rhône L303 à 334 bis : listes et répertoires des indemnités aux patriotes victimes de persécutions.

41.AC Aix : BB 113 ; BM Arles M. 812 ; AM Tarascon BB 52 ; AM Salon D1/1, D1/2, D1, 3[㹂; ; AM Marseille BB 223.

42.AD Bouches-du-Rhône L 37 à $40 ;$ L 51 à $58 ;$ L $528 ;$ L 586 ; L 879 ; L 942 à 943 ; L 1255 à 56 ; L 1507 à 1509 ; L 1905 ; L 1932 à 1949 ; L 1952 ; 1955 ; AM d'Aix, LL 79 ; AM d'Arles, D1, D2 ; AM Marseille 1D2 ; K3 art 1 ; AM Salon, 1D1 ; AM Tarascon, $1 D 1$.

43. Cette affirmation s'appuie sur note analyse approfondie des différents impôts révolutionnaires - la capitation, contribution patriotique, l'emprunt forcé de l'an IV et l'emprunt forcé de l'an VII, AD Bouches-du-Rhône 1Q 81 (liste des biens des Français émigrés) pour les villes d'Aix, d'Arles, de Marseille, de Salon, et de Tarascon, et sur Cyril BELMONTE, Les luttes politiques à Aubagne sous la Révolution française, 1789-1799, mémoire de maîtrise, Université d'Aix-en-Provence, 1999, p. 37, p. 166-168.

44. Cette affirmation s'appuie sur une étude socio-économique du personnel du département, des districts et des communes d'Aix, d'Arles de Marseille, de Salon et de Tarascon, et des comités de surveillance de ces villes.

45. Voir note 39.

46. Martine LAPIED, « Le rôle des comités de surveillance dans la circulation de l'information, à partir de l'étude des comités du sud-est », AHRF, nº 4, 2002 ; Donald SUTHERLAND, «Étude de cas : le comité de surveillance d'Aubagne », Rives nordméditerranéennes, n¹8 (2004). AD Bouches-du-Rhône L $1700 ;$ L 1702 à1703; L 1705 à 1707 ; L 1712 ; L 1718 à 23 ; L 1726 à 27 ; L 1750 ; L 1813 ; L 1813bis ; L 1856 ; L 1856bis ; L $1859 ;$ L 1862 à $1863 ;$ L 1865.

47.Pour diverses listes des prisonniers - hommes, femmes, enfants - dans les Bouchesdu-Rhône, pendant l'an II , voir L 499 ; L 501 ; L 501bis ; AM Marseille 12 (papiers de police non classés).

48.AD Vaucluse 8L 101 (dossier de François Chiavary).

49.Pour les statistiques sur les exécutions dans les Bouches-du-rhône pendant la Terreur, voir L 3122 à 3123 et 14J132 (Tribunal révolutionnaire), L 3128 (commission militaire), AD Vaucluse 8L16* (commission d'Orange). 
50.Martine LAPIED, «Les comités de surveillance : un test dans l'étude des attitudes politiques ? L'exemple du Sud-Est ", dans Mélanges Michel Vovelle, volume aixois, Aix-enProvence, Publications de l'université de Provence, 1997, p. 317-325.

51.Pour l'histoire du tribunal révolutionnaire dans le département, voir William ScoTt, Terror and Repression in Revolutionary Marseille (London, 1973) ; les statistiques ci-dessus sont tirées de ma propre analyse des papiers du tribunal et de la commission militaire. AD Bouches-du-Rhône L 3122 à 3124 匡; L 3128 à 3130 et 14J132.

52.Auguis et Serres aussi bien que Cadroy, Guérin et Chambon de vendémiaire III à fructidor III ont effectué des épurations successives de toutes les autorités constituées dans les Bouches-du-Rhône. Pour le retour des émigrés, voir $1 \mathrm{Q} 82$.

53.AN D7 4628 ; AD Bouches-du-Rhône L 1016 ; AM Marseille 13D20-21.

54.AN DIII 29, 30 ( Marseille) ; F7 4629. AD Bouches-du-Rhône 14J 105 ; L 895; L 1858 ; L 1517 à 1518 (district de Tarascon). AM Aix LL 81. BMA M 668. AM Marseille 13D 21. AM Salon II D 2/2.

55.AN DIII 30 ; F7 4628 ; 4629 ; F7 7291 ; AD Bouches-du-Rhône 14J art. 110 ; L.1014 ; L. 895医 ; AM Aix LL 81. AM Arles D 423 ; H. 128 ; AM Salon II D 2/2.

56.AD Bouches-du-Rhône L 882 ; L 950 ; L 1013 à 1014 ; L 1016 à 1018 ; L 1517à 1518 ; AM Aix, LL 65 ; AM Salon, 2D 2/2.

57.AN F1cIII Bouches du Rhône 1.

58. Voir en particulier sur ce thème, Stephen CLAY, « Le Massacre du fort Saint-Jean, un épisode de la Terreur blanche à Marseille » dans Michel VovelLE (dir.), Le tournant de l'an III : réaction et terreur blanche dans la France révolutionnaire, Paris, Éditions du CTHS, 1997, p. 579-583.

59.AD Bouches-du-Rhône L 3048 et L 3051.

60.AN BB18 189 ; AD Bouches-du-Rhône L3051; AM Aix LL81 ; AM Salon 2D3/1.

61.Cyril BELMONTE (Les luttes politiques à Aubagne sous la Révolution française, 1789-1799) a observé que cette bande était responsable d'au moins 36 assassinats, p. 169-170.

62.AD Bouches-du-Rhône L 1348 (Massacre du Fort Saint Jean).

63.AN BB18 189.

64.AN DIII 29 (Aix) ; AD Bouches-du-Rhône L 84 ; L 1018 ; L 3008 ; L 3020.

65.AD Bouches-du-Rhône L 1014.

66.AD Bouches-du-Rhône ; L 1018 ; L 1040 ; L 1059bis ; L 3038 ; L 3064 ; L 3399. BM Arles M2361; AM Aix LL81; AM Salon 2 D2/2.

67.AD Bouches-du-Rhône L 3025.

68.AD Bouches-du-Rhône L 3020 ; L 3037.

69.AN BB18 183 ; AD Bouches-du-Rhône L 377.

70.Raymonde MONNIER, «Un mot nouveau en politique : réaction sous Thermidor », dans Jacques Guilhaumou et Raymonde MonNIER (dir.), Dictionnaire des usages sociopolitiques (1770-1815), t. 6, Paris, Klincksieck, 1999, p. 127-156.

71.AN, AD XVI, 25 : Rapport fait à la Convention nationale, au nom des comités de salut public et de sûreté générale, par Marie -Joseph Chénier, séance 29 vendémiaire IV. Sur cette période critique de transition de la Convention au Directoire, voir Bernard GAINOT, "Aux origines du Directoire : le "proconsulat" de Jacques Reverchon (brumaire-ventôse an IV) », AHRF, n³32 (avril/ juin 2003), p. 129-146.

72.AD Bouches-du-Rhône L 264 à 275.

73.Alphonse AULARD, Recueil des Actes du Comité de Salut Public, avec la correspondance officielle des Représentants en mission et le registre du Conseil exécutif provisoire, 28 vols (Paris, Imprimerie nationale, 1889-1999), t. 28, p. 357, voir aussi p. 325, p. 389-90. Fréron 
a été envoyé en mission dans le département des Bouches-du-Rhône par décret de la Convention nationale du 18 vendémiaire IV (10 octobre 1795) et deux jours plus tard, sa mission fut étendue au Gard, Vaucluse, Var, Hautes et Basses Alpes. La seconde mission de Fréron a été brièvement examinée par Paul GAFFAREL, « Second proconsulat de Fréron à Marseille [31 octobre 1795 - 22 mars 1796] », La Révolution française, tome 69, 1916, p. 148-160, p. 313-336 et dans S. CLAY, « Réaction dans le Midi : le vocable de la vengeance ", dans Dictionnaire des usages socio-politiques (1770-1815), Jacques GUILHAUMOU et Raymonde MONNIER (dir.), t. 6, Paris, Klincksieck, 1999, p. 157-186, surtout p. 163-166.

74.AM Marseille 13D art 22.

75.AN F7 4629 ; BB18 174 à 175.

76.AN F7 4629.

77.AN AFIII 144B (681).

78.AN AF*III 158.

79.Sur le problème de l'ordre public dans la région en général et à Marseille en particulier, voir Stephen CLAY, « La question de l'ordre public et la politique de l'état de siège à Marseille pendant le Directoire ", dans Philippe BoURDIN et Bernard GAINOT (dir.), La République directoriale (2 vols), Paris, Société des études robespierristes, 1998, t. II, p. 861- 883 et Jonathan DEVLIN, « The Directory and the Politics of Military Command : the Army of the Interior in South-East France », French History, 4-2 (juin 1990), p. 199-223. 80.AN F7 7141.

81.Sur l'efficacité et la politisation de la garde nationale dans la région, et en France en général, pendant toute la période, voir entre autres AN, F7 7102, 7105, 7109, 7113, 7128, 7534 ; AD Bouches-du-Rhône L 95 ; L 3001.

82.SHD B13 81 : MJ au MG, 13 germinal VI.

83. Cadroy, membre du Conseil des Cinq-Cents, à ses collègues, sur le Mémoire de Fréron (Paris, thermidor IV) ; Réponse de Durand-Maillane au Mémoire de Fréron, sur le Midi (Paris, an IV) ; Isnard à Fréron (Paris, an IV).

84.Pour Willot, voir SHD 259 (d.Willot) ; Jonathan DEVLIN, « A Problem of Royalism : General Amédée Willot and the French Directory ", Renaissance and Modern Studies, 33 (1989), p. 125-143.

85.AM Marseille 13D art 24.

86.AN F7 7210 et F7 7179 ; AM Marseille 4D 35.

87.Journal des hommes libres, $\mathrm{n}^{\circ} 98$ (23 nivôse V), $\mathrm{n}^{\circ} 124$ (19 pluviôse V), L'Ami du peuple, $n^{\circ} 301$ (2 pluviôse V). Le séjour controversé de Willot à Marseille fut l'objet de nombreux et féroces débats entre les deux principaux journalistes de la ville, Ferréol Beaugeard et Pierre Peyre-Ferry. S. CLAy, «La guerre des plumes », op. cit.

88.AN F7 7296.

89.AN BB18 183.

90.AN F7 7164.

91.Journal des hommes libres, $\mathrm{n}^{\circ} 148$ (13 ventôse V), p. 603.

92.L'Observateur du Midi, $\mathrm{n}^{\circ} 33$ (10 ventôse V), 131.

93. Chaque incident fit l'objet de procédures criminelles volumineuses, voir $\mathrm{AD}$

Bouches-du-Rhône L 3052 et L 3053.

94.AD Bouches-du-Rhône L 3053 : Déclaration des témoins, déclaration Rose Traverse, 12 thermidor V.

95.AD Bouches-du-Rhône L 270 à 272 ; AM Marseille K3 art 9 et 10.

96.AN F7 7340 ; F1bII(Bouches-du-Rhône)1 ; F1cIII (Bouches-du-Rhône)1 ; AN AFIII 217. 
97.AN BB18 178 ; BB18 189 ; F7 7328 ; F7 7347 ; F7 7379 ; F7 7352 ; F1bII BDR 16

(Marseille).

98.AN F9 40 (Bouches-du-Rhône).

99.AD Bouches-du-Rhône L 295.

100.AM Marseille 4D 28.

101.AN BB18 177 ; BB18 189 ; AD Vaucluse 7L 85 ; AD Bouches-du-Rhône L 3051 ; L 3089 ;

$5 \mathrm{U} 8$; pour le jugement de l'affaire d'Aubagne, voir $2 \mathrm{U} 3 / 9$.

102.AN F7 7428 ; BB 18183 ; AD Bouches-du-Rhône L 296.

103.AN F7 7346 ; F1cIII Bouches-du-Rhône 7.

104.AM Marseille 13D article 34.

105.AN F7 3659 (4) ; BB18 174 à 189 et AD Bouches-du-Rhône L 173, L 3001.

106.Proclamation du directoire exécutif aux Français, sur les assemblées primaires, 17 ventôse VII.

107.Sur le problème du brigandage et de l'ordre public dans le Sud-Est pendant le directoire et le Consulat, voir Stephen CLAY, « Le brigandage en Provence sous le Directoire et le Consulat, 1795-1802», dans Du Directoire au Consulat 3 : Brumaire dans l'histoire du lien politique et de l'État-nation, Jean-Pierre JESSENNE (dir.), Villeneuve d'Asq, CRHENO, 2001, p. 67-89.

108.AN F7 7688 F7 7694 ; AD Bouches-du-Rhône L248 ; AM Marseille 1D 25.

109.AN F7 7292.

110.AN F1cIII Bouches-du-Rhône 7.

111.Benjamin CONSTANT, Des Réactions politiques, Paris, Champ-Flammarion, 1988.

112.Alphonse AULARD, Recueil des Actes du Comité de Salut Public, avec la correspondance officielle des Représentants en mission, 28 vols., Paris, 1889-1918, vol. 23, p. 291.

\section{RÉSUMÉS}

Le Midi provençal fait partie des régions les plus troublées et violentes de la France révolutionnaire. La majorité de ces troubles fut le produit d'une "lutte des deux partis", sanglante et prolongée, une guerre entre des factions rivales à l'intérieur des communes de Provence, petites et grandes, qui perdura avec une intensité diverse pendant la décennie révolutionnaire. En effet, chaque phase de la Révolution dans le Sud-Est fut la cause et la conséquence de conflits préexistants qui impliquaient souvent les mêmes hommes et femmes, alternativement oppresseurs et opprimés. Le phénomène politique de la «réaction » a longtemps été associé au Midi dans l'historiographie de la Révolution française. Généralement circonscrite à l'an III et à la description des attaques contre les hommes et les institutions de la Terreur, dépeinte comme fondamentalement royaliste, la réaction ou plutôt les réactions constituent un phénomène beaucoup plus complexe. Cet article examine les origines et la nature des différentes réactions dans le département des Bouches-du-Rhône ainsi que les factions elles-mêmes dans les principales communes du département. Il montre comment les différentes institutions - civiles, militaires et judiciaires -, largement politisées, furent utilisées dans la guerre entre les partis. L'auteur propose la «réaction» comme concept opératoire pour comprendre les conflits 
politiques et la violence dans la région pendant la décennie révolutionnaire, un modèle d'analyse qui peut s'appliquer à d'autres régions de France.

Stephen Clay, The «Reactions» in the Midi: Conflict, Continuity, and Violence. The Midi Provencal ranks among the most persistently troubled and violent regions of Revolutionary France. Most of this turbulence was a product of a bloody and prolonged «lutte des deux partis» a war between rival factions within provencal communes large and small, lasting in varying degrees of intensity throughout most of the Revolutionary decade. Indeed, each phase of the Revolution in the Southeast was largely the cause and consequence of pre-existing conflicts often involving the same men and women, alternatively oppressors and oppressed. The political phenomenon of the «Reaction» has longed been associated with the Midi in the historiography of the French Revolution. Normally restricted to the year III to describe an attack on the men and institutions of the Terror, and depicted as fundamentally "royalist», the reaction-or better, reactions- were in fact more complex. This article examines the origins and nature of the different reactions in the department of the Bouches-du-Rhône as well as the factions themselves in many of the major communes, and shows how different institutions -civil, military, judicialwere used and politicized in the war between the partis. The author proposes the concept of «Reaction» as the best mode of understanding political conflict and violence in the region during the revolutionary decade, an analytic model with far -reaching implications for other parts of France.

\section{INDEX}

Mots-clés : justice, Terreur, violence, Midi, Bouches-du-Rhône, Réaction, vengeance, faction, révolte fédéraliste

\section{AUTEUR \\ STEPHEN CLAY}

Institut d'études politiques de Paris, 27, rue Saint-Guillaume, 75337 Paris cedex 07, sclay@club-internet.fr 